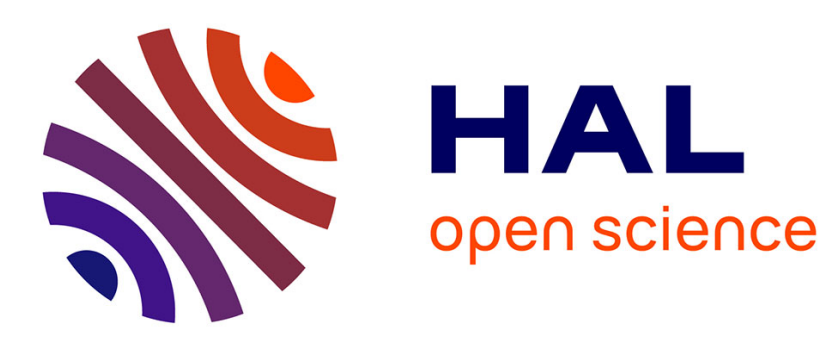

\title{
A generic formalism for the semantic modeling and representation of architectural elements
}

\author{
Livio de Luca, Philippe Veron, Michel Florenzano
}

\section{To cite this version:}

Livio de Luca, Philippe Veron, Michel Florenzano. A generic formalism for the semantic modeling and representation of architectural elements. The Visual Computer, 2007, 23 (3), pp.181-205. 10.1007/s00371-006-0092-5 . hal-01020092

\section{HAL Id: hal-01020092 https://hal.science/hal-01020092}

Submitted on 28 Apr 2015

HAL is a multi-disciplinary open access archive for the deposit and dissemination of scientific research documents, whether they are published or not. The documents may come from teaching and research institutions in France or abroad, or from public or private research centers.
L'archive ouverte pluridisciplinaire HAL, est destinée au dépôt et à la diffusion de documents scientifiques de niveau recherche, publiés ou non, émanant des établissements d'enseignement et de recherche français ou étrangers, des laboratoires publics ou privés. 


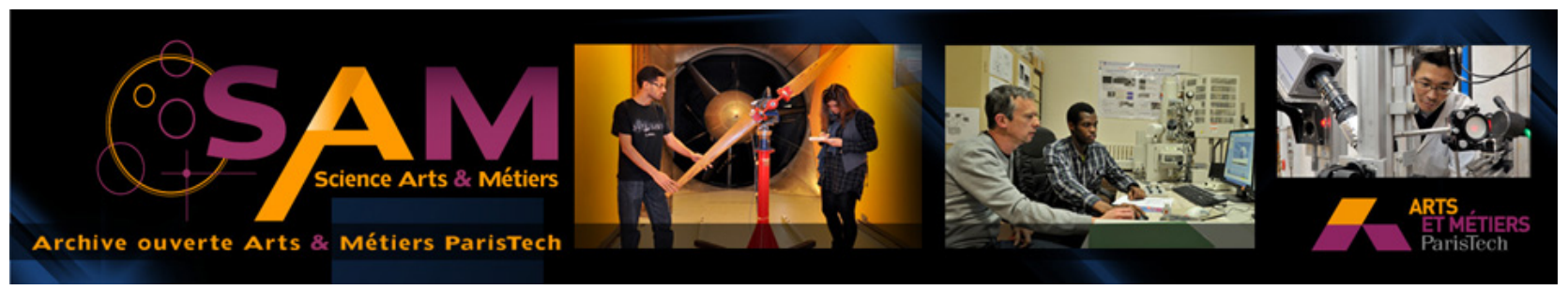

Science Arts \& Métiers (SAM)

is an open access repository that collects the work of Arts et Métiers ParisTech researchers and makes it freely available over the web where possible.

This is an author-deposited version published in: http://sam.ensam.eu

Handle ID: .http://hdl.handle.net/10985/8326

\section{To cite this version :}

Livio DE LUCA, Michel FLORENZANO, Philippe VERON - A generic formalism for the semantic modeling and representation of architectural elements - Visual Computer - Vol. 23, n`3, p.181-205 $-2007$ 


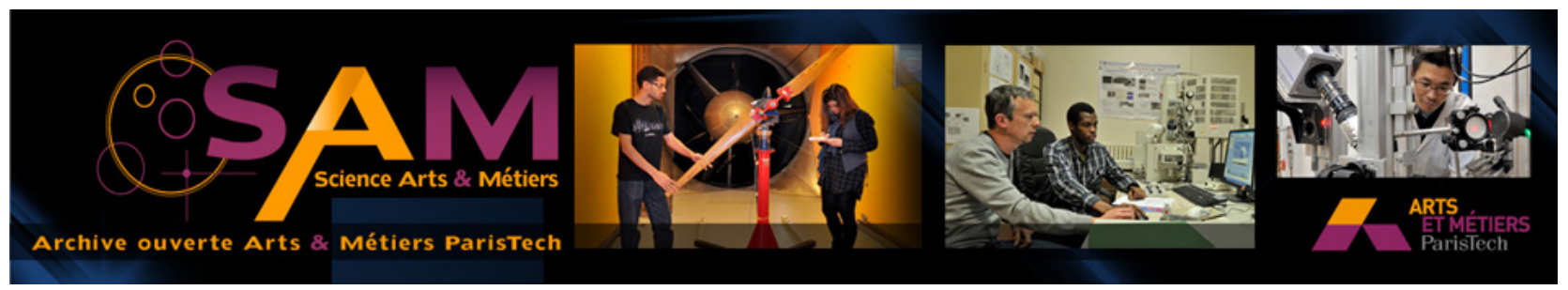

Science Arts \& Métiers (SAM)

is an open access repository that collects the work of Arts et Métiers ParisTech researchers and makes it freely available over the web where possible.

This is an author-deposited version published in: http://sam.ensam.eu Handle ID: .http://hdl.handle.net/10985/8326

\section{To cite this version :}

Livio DE LUCA, Michel FLORENZANO, Philippe VERON - A generic formalism for the semantic modeling and representation of architectural elements - Visual Computer - Vol. 23, n³, p.181-205 $-2007$ 
Livio De Luca

Philippe Véron

Michel Florenzano

\section{A generic formalism for the semantic modeling and representation of architectural elements}

\begin{abstract}
This article presents a methodological approach to the semantic description of architectural elements based both on theoretical reflections and research experiences. To develop this approach, a first process of extraction and formalization of architectural knowledge on the basis of the analysis of architectural treaties is proposed. Then, the identified features are used to produce a template shape library dedicated to buildings surveying. Finally, the problem of the overall model structuring and organization using semantic information is addressed for user handling purposes.
\end{abstract}

Keywords Architectural heritage . Architectural knowledge - Surveying $\cdot$ Feature-based modeling . Semantic shape

\section{Introduction}

Studies on architectural heritage can be supported today by three-dimensional reconstructions of real buildings. The 3D digital model can bring an effective support to documenting the current state of historical buildings and also to create resources for the researchers who lead analyses on their historical evolution. With the purpose of confirming this assumption, several problems must be approached. As a result of using instruments such as the laser scanner for the building documentation, making the 3D models of architectural elements focuses on automatic procedures of reconstruction which consist primarily in a geometrical interpolation of metric data [27]. However, the objective of an architectural representation is to lead a semantic reading of the recorded data through the geo- metrical interpretation of the shape it describes. So, in order to attain these objectives, the process of threedimensional restitution of an observed reality must necessarily refer to a universe of knowledge. It is thus necessary to reaffirm the historical distinction between the acquisition phase and the data interpretation phase [28] while taking into account the relations of dependence that exist between these two stages. To give an example, many patrimonial buildings testify an intensive use by their builders of the concept of moulding. The importance of this concept is, for the architectural theory, largely established: it is described there initially as an essential tool in the composition of the shapes, but also as the means by which the shape gathers sense, by which the shape adds to its geometry properties of significant expression - softening, underlining, etc. In this direction, the coherence of the procedures of digital processing compared to the codes 


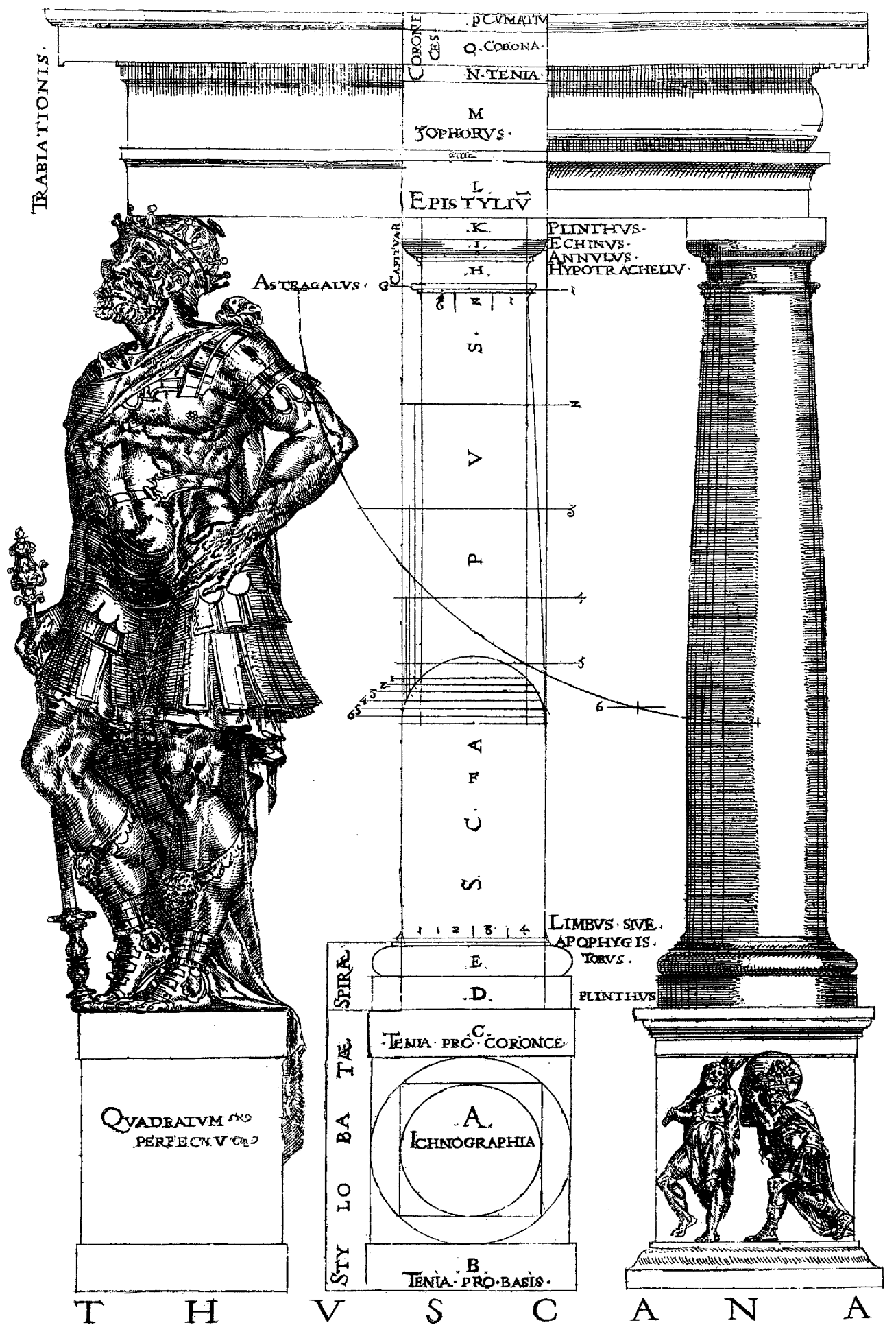

Fig. 1. Representation of the Tuscan order in the John Shute's treaty "The First and Chief Grounds of Architecture". London, 1563

of the architectural representation constitutes an important issue we will address. In this article, we present an approach and the tools we have developed for the geometrical and semantic description of classical architecture elements. This approach guides the development of two applications: ${ }^{1}$ a tool for the three-dimensional reconstruction of buildings, starting from a joint acquisition by laser scanning and photography, and a system for consulting on

${ }^{1}$ For more information see http://www.map.archi.fr/nubes. 
the Internet of the surveying and of the representations. This article is organized as follows: Section 2 presents the basic concepts for the understanding of geometrical nature of elements of classical language. Section 3 describes a generic formalism for geometrical and semantic description of profiled elements while Sect. 4 tackles the problem of the semantic structuring of the model with the aim of exploiting the description model for multiple objectives of analysis.

\section{Basic concepts to understand the geometrical nature of the elements of classical architecture}

\subsection{Architectural surveying as a reverse-engineering process}

The analysis of an architectural shape may be led by the identification of the process allowing its geometrical construction. However, the codes of architectural representation can always help in this stage which remains the most difficult phase of building reconstruction. To give an example one can quote the geometrical representation of a column (see Fig. 1). This element, far from being a simple cylinder, is characterized by a pace (truncated, bent bottom, bent third, or reinflated) and transitions as the cimbia (moulding softening the meeting of the shaft with the base) or the astragale (body of mouldings separating the capital from the shaft) [23]. Moreover, certain proportions regulate its dimensions [9]. This type of observation can be made for almost every part of a building. The study of the form has a double finality: the first one is the representation, the second one is the surveying of the object. If one analyzes these two moments of the analysis, one easily realizes that they are in a strictly interdependent relation which is neither hierarchical, nor sequential. To draw an element its shape should be known, to know its shape it should be measured, but to measure it, it is necessary to decipher its geometrical nature [18]. In this sense, one of the most effective ways to define the architectural surveying is to regard it as the rebuilding of the project. The surveying is indeed a reverse process in which, starting from an existing object, one rebuilds the process of its realization, and one interprets the idea of design which is upstream of its realization.

\subsection{Five key concepts to understand the geometrical nature of classical buildings}

The application of the geometry to the description and analysis of the architectural shape obliges to reduce the multiplicity to intelligibility. Examples of this approach may be found in various fields and applied to the geometrical understanding of shapes or varied phenomena [4]. In the same way, starting from a geometrical analysis of the various parts of a building and by having as an objective its geometrical and semantic description, we have proposed a method for the geometrical reconstruction starting from profiles [5]. This method is founded on the analysis of invariant and morphological specificities one can extract from a semantic cutting of the building. We saw that throughout the history of architecture, the morphological complexity of the shapes was always influenced by the methods of geometrical control that made their conception possible. Examples of these methods are the descriptive geometry [20], or stereotomy [6,34]. Based on a study of the principles subjacent to these control methods of the architectural shape, one can then identify on one side relevant information to extract from a survey (profiles in a point cloud for example) and on the other side the process of construction better adapted to ensure the geometrical restitution of the elements.

Here, starting from an analysis of the architectural treaties relating the classical language $[1,21,29]$, we identify five key concepts for understanding the geometrical nature of classical buildings and for the restitution of their shape.

- Dominant surface. Each building presents a dominant surface which characterizes its space extension and its principal internal divisions (see Fig. 2).

- Transition. In the classical language, architectural shapes are based on geometrical transitions. Profiles

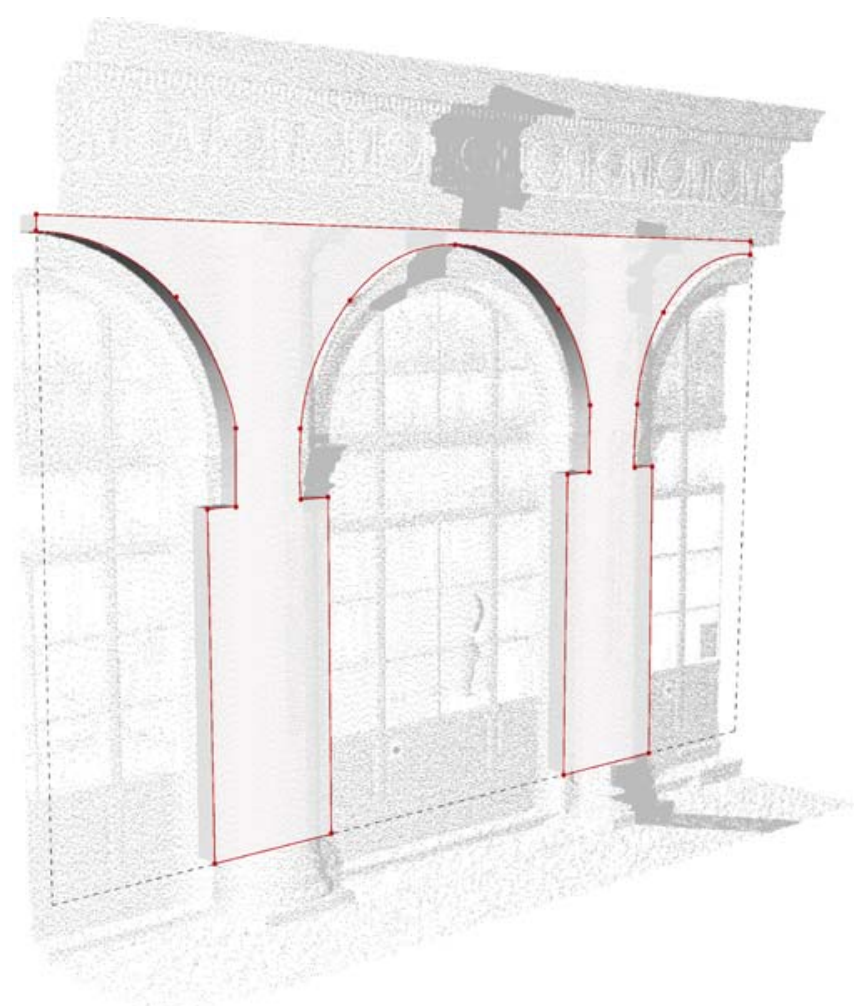

Fig. 2. Reconstruction of a dominant surface 
shared by two elements are then to be distinguish in the general composition. In the specific case of the 3D reconstruction, the problem consists in identifying the transitions between the elements throughout a dominant direction (see Fig. 3).

- Plans of construction. For Quintrand et al. [24], although the objects handled by the architects during the centuries are primarily three-dimensional, figurative practice in design always has as support the plan. The profiles extracted from relevant plans (see Fig. 4) thus constitute the descriptors of surfaces that can be generated by traditional functions of modeling (sweeping, revolution, interpolation, etc.).

- Repetition. The composition of a great number of architectural buildings is based on the distribution of repeated elements. These elements are often organized following geometrical layouts: symmetry, rhythm and other rules of composition can for example organize elements following a dominant direction. Moreover, these repetitions can interest various scales: the hierarchical relations that the architectural composition expresses organize the typified elements around the concepts of order, module, stage, or frontage. With regard to the classical language this organization results from the fundamental principles of the architectural composition [36].

- Mouldings. Understanding the role the mouldings play in the definition of the shape of classical architecture elements is essential [33]. Firstly, that makes it possible to rebuild profiles by comparing them with a description language that belongs to the architectural representation. Secondly, that makes it possible to describe the building as a collection of objects identified by a precise

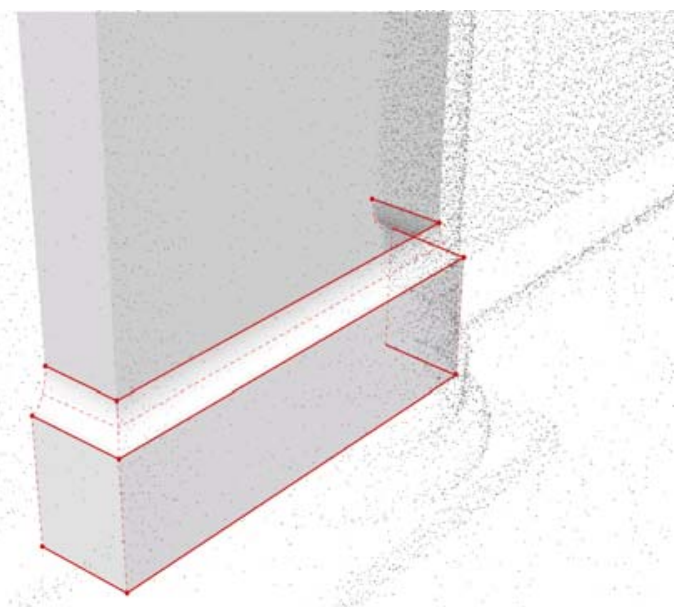

Fig. 3. Reconstruction of a transition

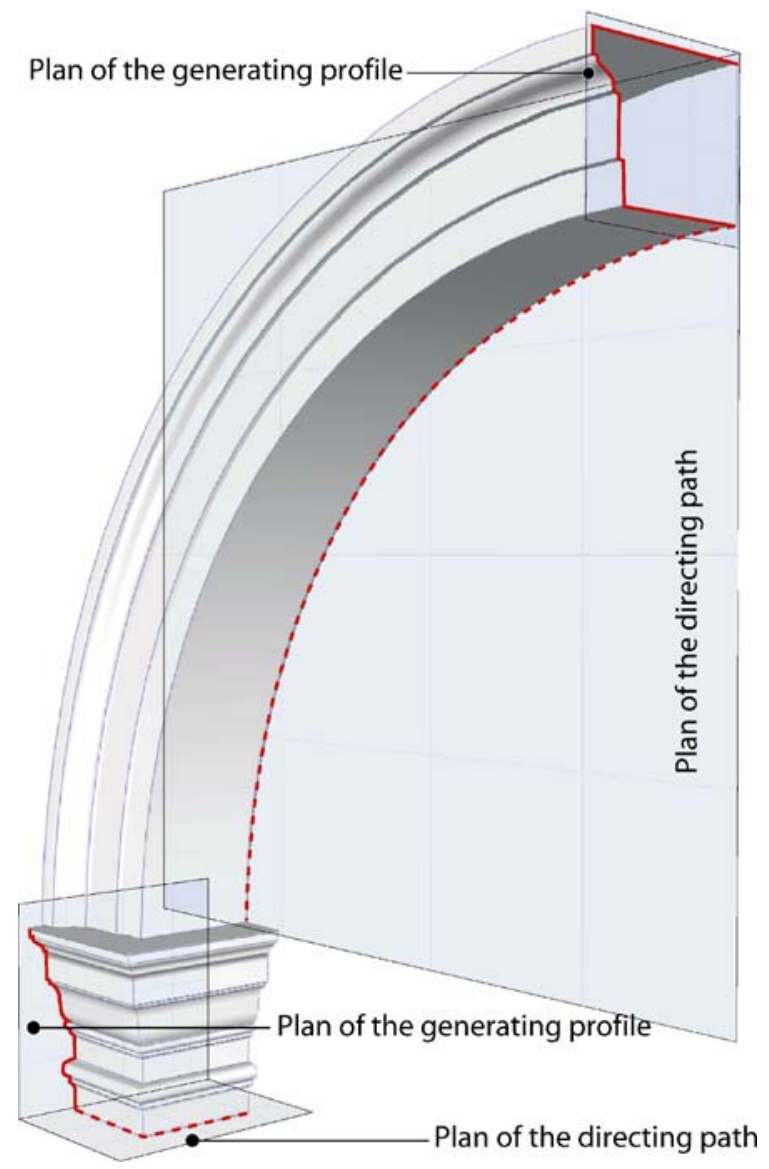

Fig. 4. Reconstruction of an architectural element by construction plans

vocabulary. Finally it makes it possible to better interpret the data of the surveying and to avoid producing profiles deprived of sense from the point of view of the architectural analysis.

To treat in a relevant way the restitution of the profiled elements, it is now necessary to look further into the aspects concerning the role of architectural knowledge in the interpretation of the shape.

2.3 Mouldings: atomic units of the classical architecture

The problem of the formalization of the geometrical nature of architectonic objects consists above all in the identification of the atomic entities that compose them. However, a classification of these basic elements cannot be led by an analysis of the morphology that refers to the descriptive systems used for their design. It is thus necessary to call upon the treaties of architecture, according to the period the studied object belongs to. Rattner [26] developed a classification of the mouldings showing in a systematic way the role they play in the design of clas- 


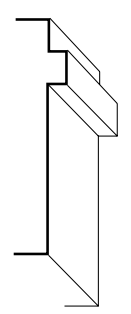

a fillet

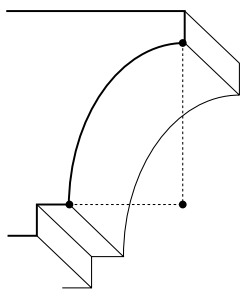

c cavetto

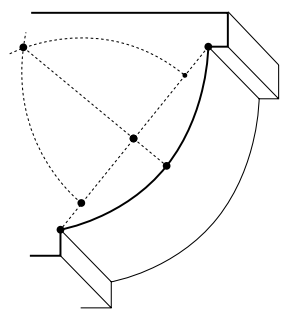

f ovolo

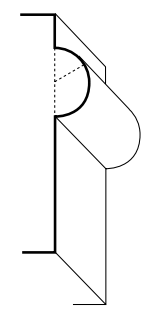

i astragal, head

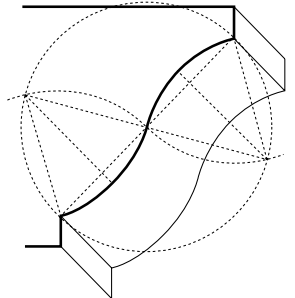

n cyma recta

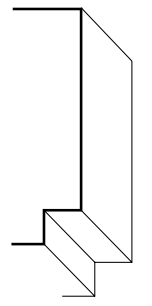

b fascia

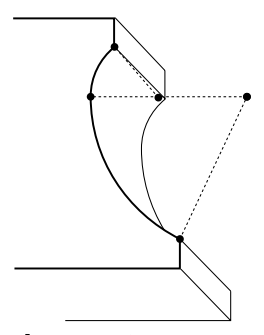

d scotia

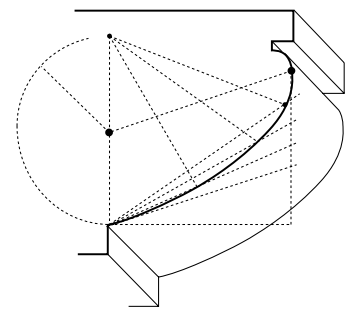

g echinus

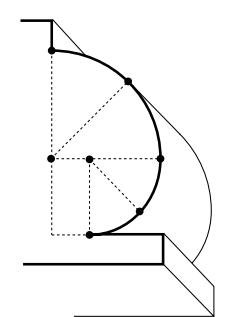

I thilmb

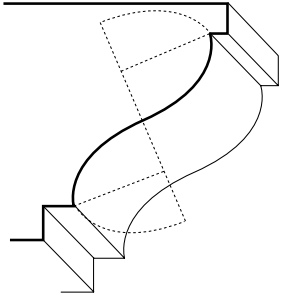

- cyma reversa

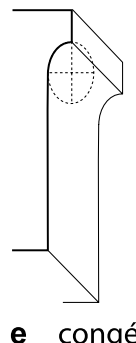

e congé

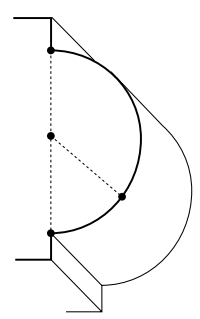

h torus

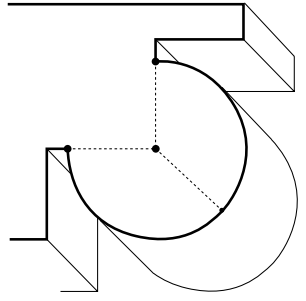

m $3 / 4$ head

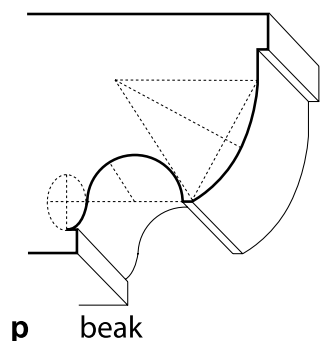

Fig. 5. Classification of mouldings of the classical language suggested by Rattner [26]

sical buildings. The author defines the mouldings as the smallest physical units - the atoms - of the classical architecture and provides a way to understand the shape of the architectural elements according to their combination. This classification is based on a variety of 14 mouldings (see Fig. 5) and uses several criteria of regrouping. At the most elementary level, one can gather this variety of atoms according to the analysis of the shape. One distinguishes initially the straight mouldings, then the concave ones, the convex ones and finally the complex (see Fig. 5 from the left column to the right). One can also gather the same variety of mouldings, according to their architectural function in the composition of the building. In Fig. 6a a basic moulding is first used as a visual "foot" with the weight of the wall that rises above. Then it modulates the transition between the vertical and horizontal planes of the wall and floor, and finally it punctuates the bottom of the wall.
In Fig. 6b, the entablature, as all the elements extended on a important dimension (vertical or horizontal) of the frontage, aim to create structurally significant divisions of surface. In Fig. 6c, while it is illogical to have two different scales in a particular sequence of mouldings, it is common to have profiled elements pertaining to various scales. In the classical buildings one generally distinguishes two main scales that mark the relation between human and architectural dimension. From a geometrical point of view, the aspect that interests us most is certainly the coordination - the relative localization of a moulding, like its proportions, implies the coordination of various parts to compose an ordered unit. This is usually reached by means of alignments of plans. In the example of a base (see Fig. 7), when a torus is placed above a plinth, its external point is typically aligned to the prolonged vertical plan of the surmounted element. A horizontal axis on the basis of the barycenter of the torus in intersection with this 


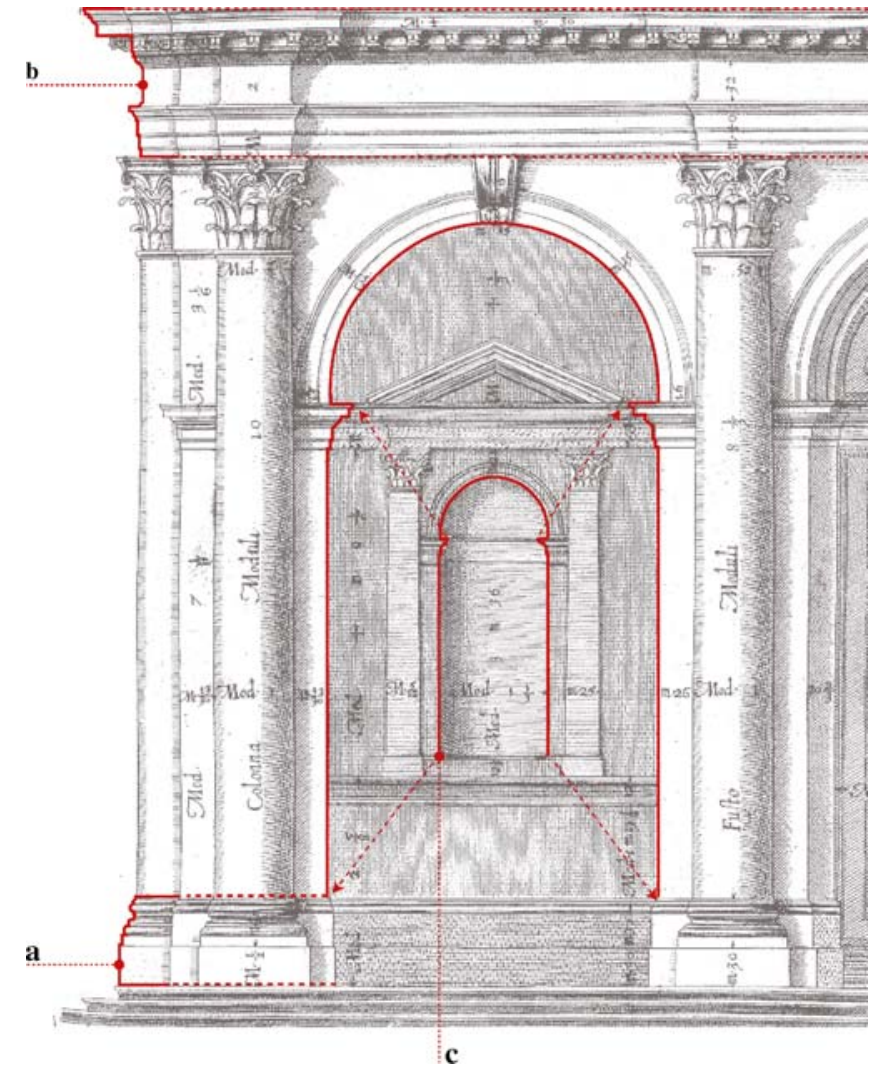

Fig. 6. Diagram illustrating the role of mouldings in the composition of a classical building. Illustration elaborated on a drawing of the Scamozzi's treaty. Venice, 1615

plan then identifies the point of tangency of the half-round pearl that characterizes its profile.

\section{Formalization of architectural primitives}

\subsection{General remarks}

In this section, we present the method developed to formalize architectural primitives starting from the analysis of historical sources. The starting point of the formalization lies in the observation of the geometrical nature of the majority of classical elements. Indeed, in several cases, their shape derives from the revolution around an axis or the extrusion of a profile with a strongly ordered and connected geometry. The definition of our approach of formalization takes into account three distinct dimensions:

- The interpretation of knowledge relating to the shape

- The definition of the methods allowing its geometrical modeling

- The identification of the relations between the constitutive parts of the shape

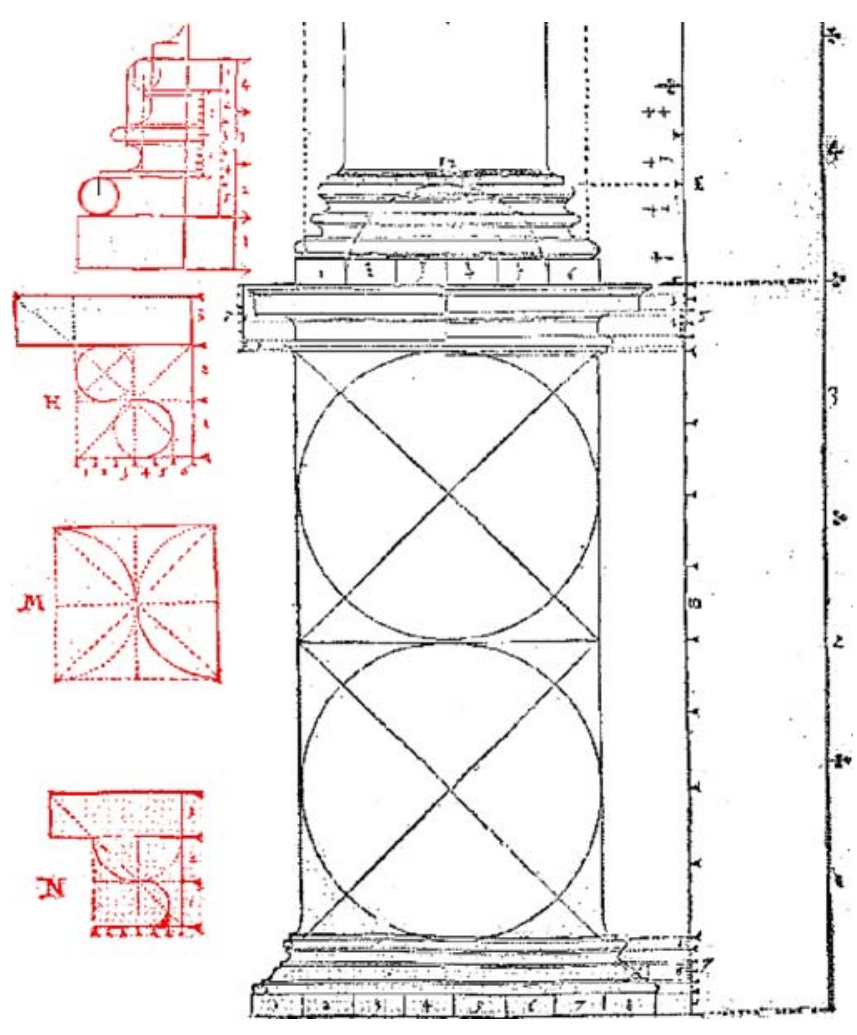

Fig. 7. Construction of the Composite order in the Blum's treaty. Zurich, 1550

Several authors contributed to the classification of profiled elements $[12,23,26]$. These classifications concentrate, however, on the analysis of the composition language over a specific period. Moreover, as the authors indicate it, a certain number of mouldings results from the combination of basic mouldings. With the geometry like central point of view, a comparative analysis of the traditional mouldings enables us to extract a series of reports:

- Any moulding results from a combination of linear segments and/or arcs.

- Any transition in a profile (or inside a moulding) is based on the orthogonality between two construction plans.

- Any curved part in a moulding (concave or convex) results from the deformation of its bounding box or from a polycentric construction of tangent arcs.

In regard to the surfaces of a profiled element, one can observe that:

- Any surface results from a generating profile and a directing path.

- The generating profile and the directing path are always in condition of orthogonality (even when the second one is a curve). 
- Any directing path results from the combination of the same geometrical entities that compose the mouldings, on a different scale.

It is on these reports that we base our approach of the analysis of the formalization of knowledge related to the architectural shape, with an aim of extracting the fundamental principles of its geometrical construction. However, the shape division resulting from the requirements of geometrical modeling is inevitably not coherent with the one that allows its semantic description. An architectural term can for example identify a part of the object whose surfaces are generated starting from two distinct modeling procedures. To solve this problem we organize the formalization of the element according to the relations between two parallel levels of description: geometrical and semantic. The first makes it possible to rebuild the shape in three dimensions; the second makes it possible to organize its parts according to the vocabulary of the architect. As we have the requirement to handle the entities we formalize in three dimensions, we base our approach on the development of a network of nodes developed in MEL (Maya Embedded Language). A node is a structure that can organize, receive and provide information through its attributes. A polygonal surface or NURBS (non-uniform rational $B$-splines) can be recorded in a node in the form of an attribute. By connecting simple nodes a computation channel is created in the DG (dependency graph) that will produce the final result. The DG is based on a push-pull model: when one provides data to a node, it causes an update of all the nodes which receive and/or process these data [13].

\subsection{Geometrical description}

With an aim of extending the framework of formalization to a higher number of cases (possibly relative to other historical periods) we introduce a level of description lower than that of the mouldings: geometrical atoms. They constitute a set of geometrical primitives that, by combining, allow the reproduction of any kind of moulding of the classical architecture language (see Fig. 8). These atoms are the only entities of the formalization for which we provide geometrical information (control points of a line or of a curve): indeed, the generation of the whole surface of the element is based exclusively on constraint relations, grouping operations and modeling functions. Geometrical description is based on the relations between three types of nodes which describe the construction of the element from the definition of its geometrical atoms until the complete generation of its surfaces.

- Atoms. This node is characterized by a structure of information concerning the geometrical construction, spatial transformation and constraints of an atomic entity.

- Profiles. This level allows grouping the mouldings according to the plans of construction.

- Surfaces. This level uses specific nodes for the generation of surfaces starting from the profiles.

\subsubsection{First level: geometrical atoms}

A node atom contains essential information for its representation in space (position, rotation, scale) and controls four under-nodes which share attributes (see Fig. 9):

- The bounding box constitutes a deformable support on which an atom is built. It is based on a 9-point grid that is also used as dimensional unit of reference.

- The origin defines the first control point of the geometrical atom.
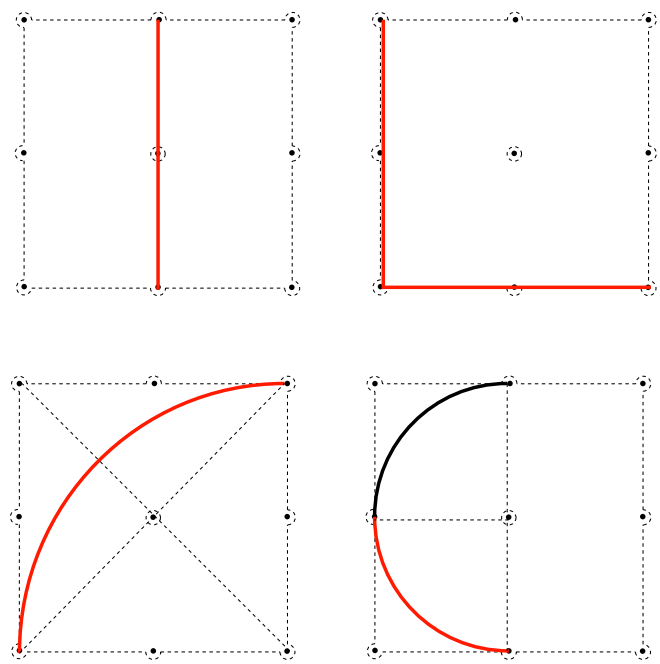
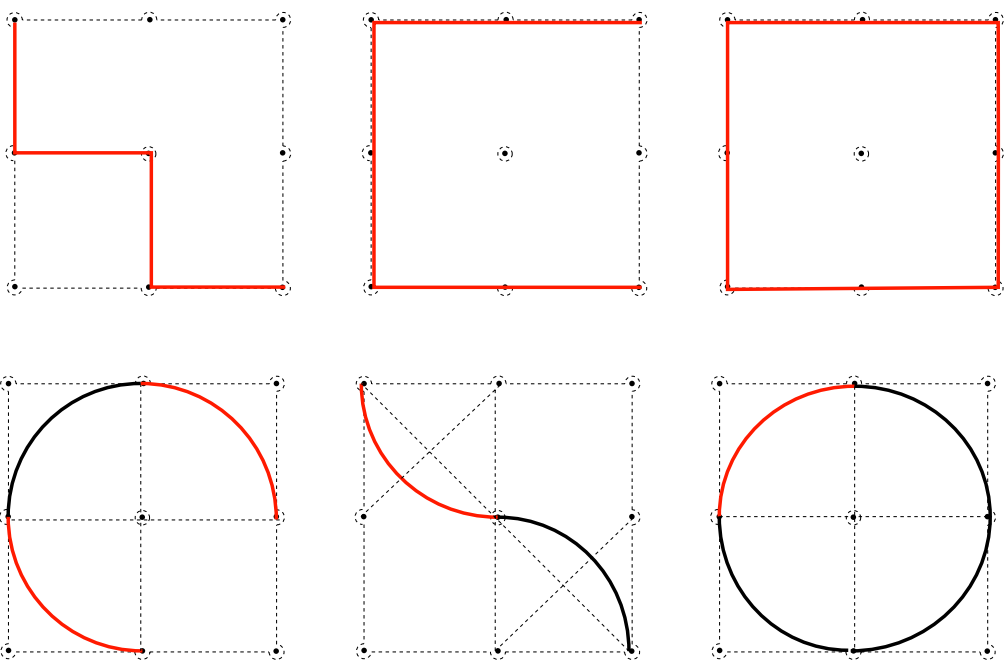

Fig. 8. Geometrical atoms for the construction of mouldings of classical architecture 

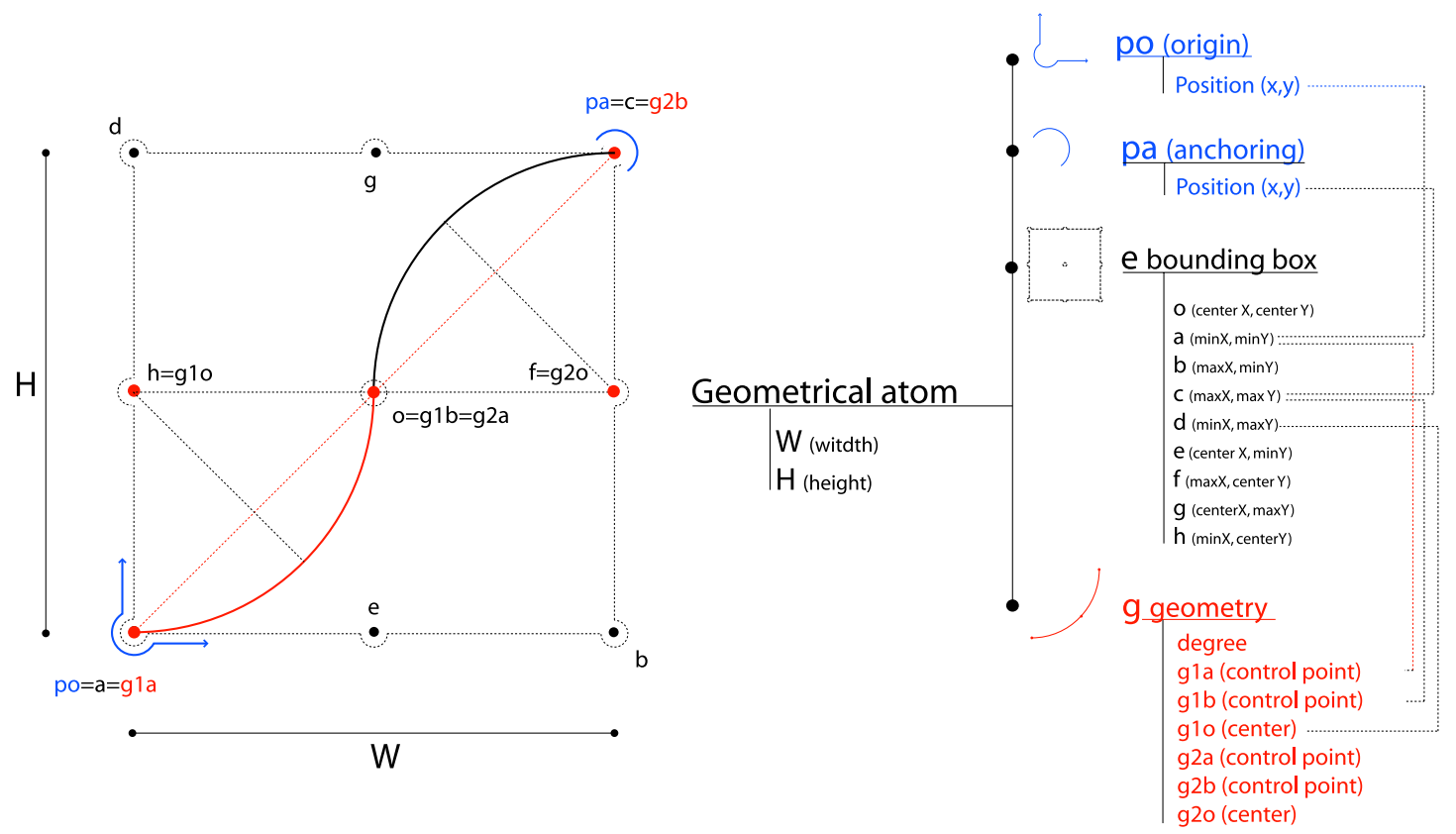

Fig. 9. Diagram of relations of the "geometrical atom" node's attributes

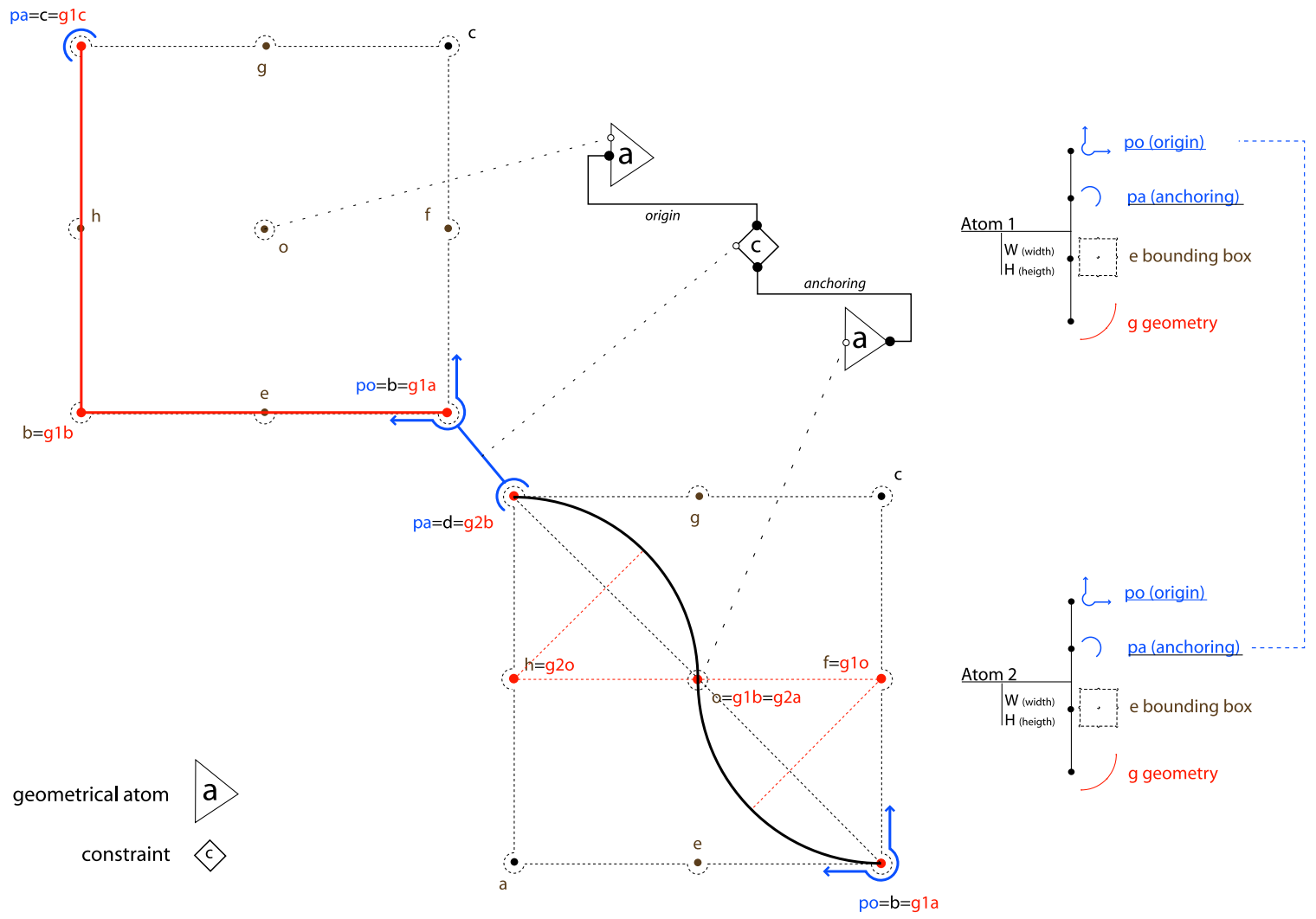

Fig. 10. Diagram of attribute connections between two "geometrical atom" nodes 
- The anchoring defines its last control point and is exploited to constrain the position of the atom that is connected to it.

- The geometrical representation contains the control point of a $B$-spline curve defining the geometry of the atom.

\subsubsection{Second level: profiles and paths}

The second geometrical level of description results from a combination of atoms. This combination is based on an upward aggregation according to the vertical axis of a construction plan and it is carried out by a heritage of the position attribute (translation vector): the origin node of an atom is constrained with the anchoring node of the atom which precedes it in the chain (see Fig. 10). To generate profiles, on each level of the progressive combination, we modify the attributes of width and height of the corresponding atom. These attributes deform the bounding box of the atom to which the geometrical representation is connected. Figure 11 shows the modeling of one of the most complex mouldings: the beak. The re-

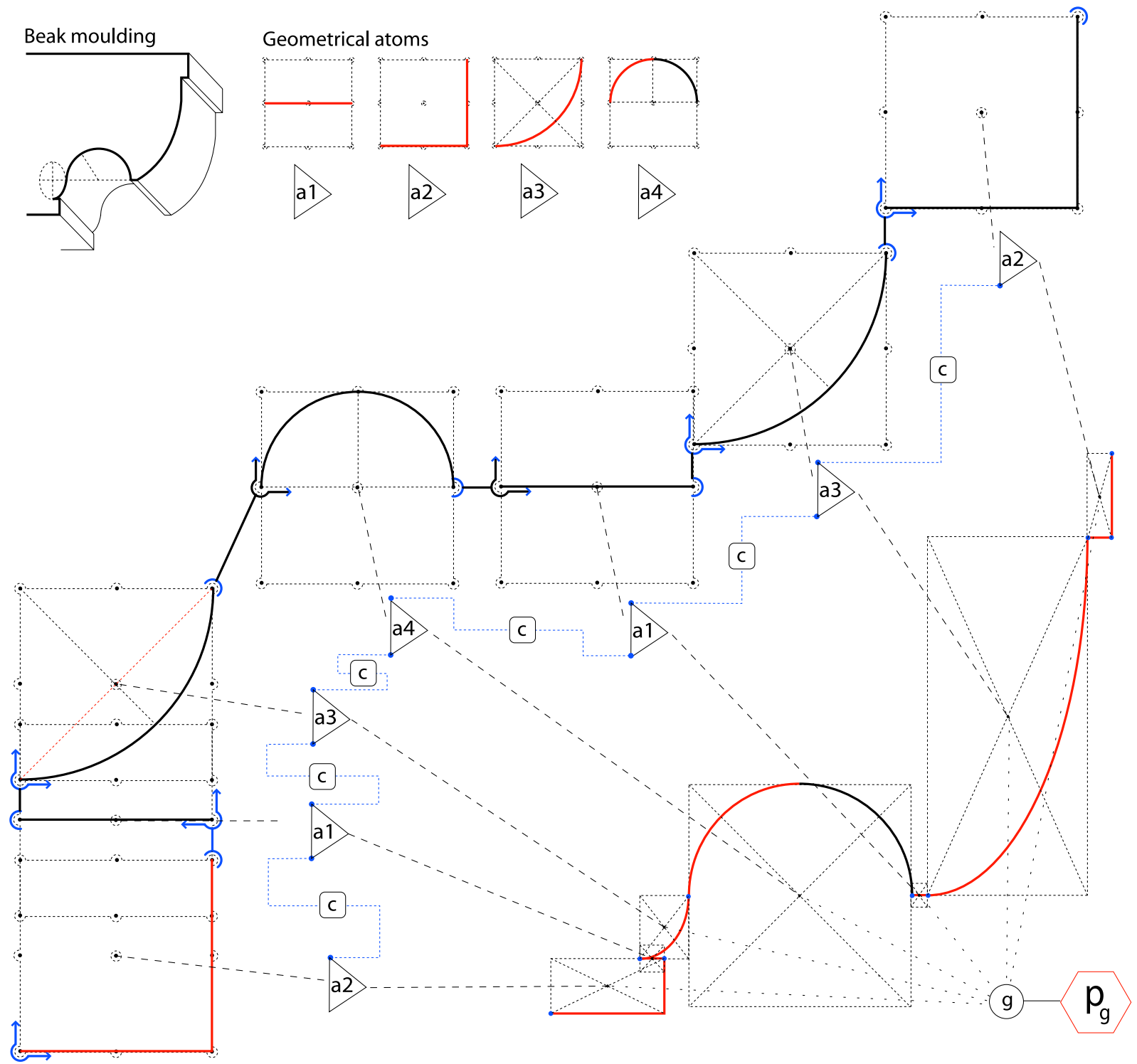

a) geometrical atom (c) constraint (9) group $\left\langle p_{g}\right.$ generating profile

Fig. 11. Construction of a moulding by combination of a set of geometrical atoms 
grouping of the atoms in profiles is established according to the common modeling functions. For most elements
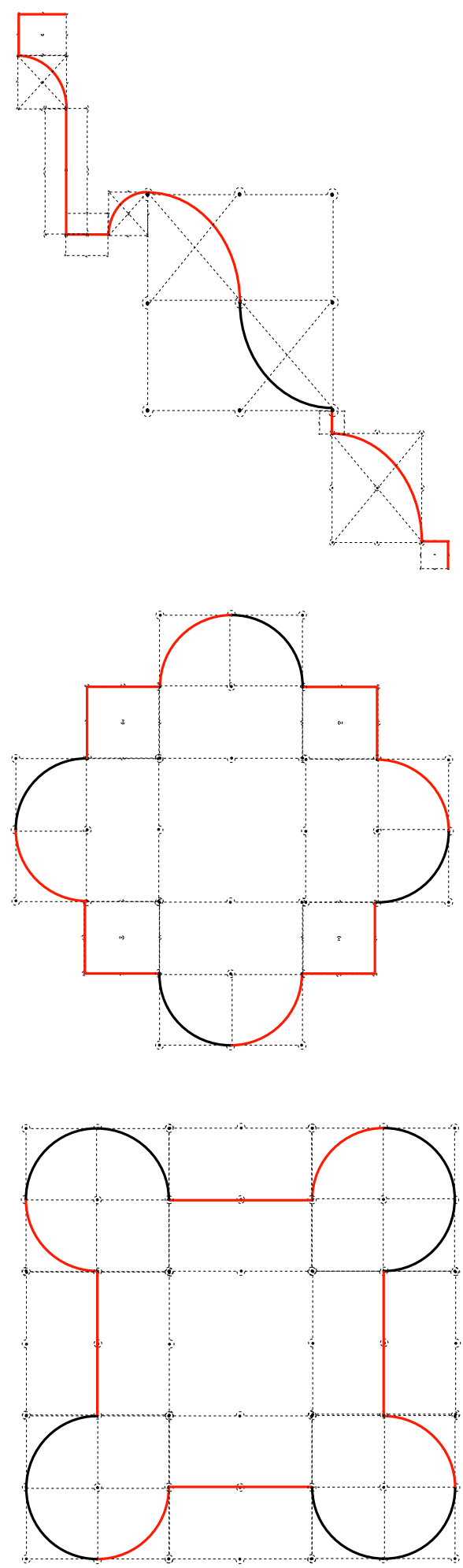

Fig. 12. A vertical profile and two horizontal build by combination of geometrical atoms two profiles are sufficient. It is necessary to identify the generator and the director of surface. As in the case of the generating profile node, the directing path node can also be defined by combination of geometrical atoms (see Fig. 12).

\subsubsection{Third level: surfaces}

This level of the geometrical description is based on the concept of construction history: a property of our development environment that we exploit to save information concerning the entries of a modeling process. Surface is indeed generated by a modeling function node (linear, curved or combined extrusion), which receives geometrical information from a generating profile node and a directing path node. Once the surface is generated the two entry nodes are consequently connected to the node surface. That allows updating the surface according to each transformation of an atom. We base the procedures of modeling on three extrusion functions (see Fig. 13). In the three cases the geometry of the generating profile is swept along the directing path. The alternatives relate to the composition of the directing path and the degree of the resulting surface. We break up the directing path according to this last attribute. The generation of surface advances per piece, and, when a change of degree (from $1^{\circ}$ to $3^{\circ}$ or vice versa) is detected, a new surface is created in agreement with the degree of the directing path. This new surface uses as generating profile the last isoparametric curve of the preceding surface. That ensures continuity between the various pieces of surface. The same technique is used to create planar filling on the ends of the surfaces.

3.2.4 An example of formalization: a doric capital from the Palladio's treaty

Figure 14 shows the geometrical construction of a doric capital described in the Palladio's treaty [21] and obtained by a simple combination of geometrical atoms gathered in two generating profiles and extruded along two directing paths. For the formalization of the element, we use the description provided by the author and on the relative drawing (see Fig. 15): we connect node atoms according to the described mouldings. Once the mouldings are suitably proportioned - this is possible at the same time by using the dimensions present on the drawing - we gather them in two generating profile nodes according to the respective modeling procedures.

\subsection{Semantic description}

Semantic description is defined by a structure of concepts organized around geometrical description. The nodes of the semantic description are connected on one side to an architectural term, and on the other they gather 

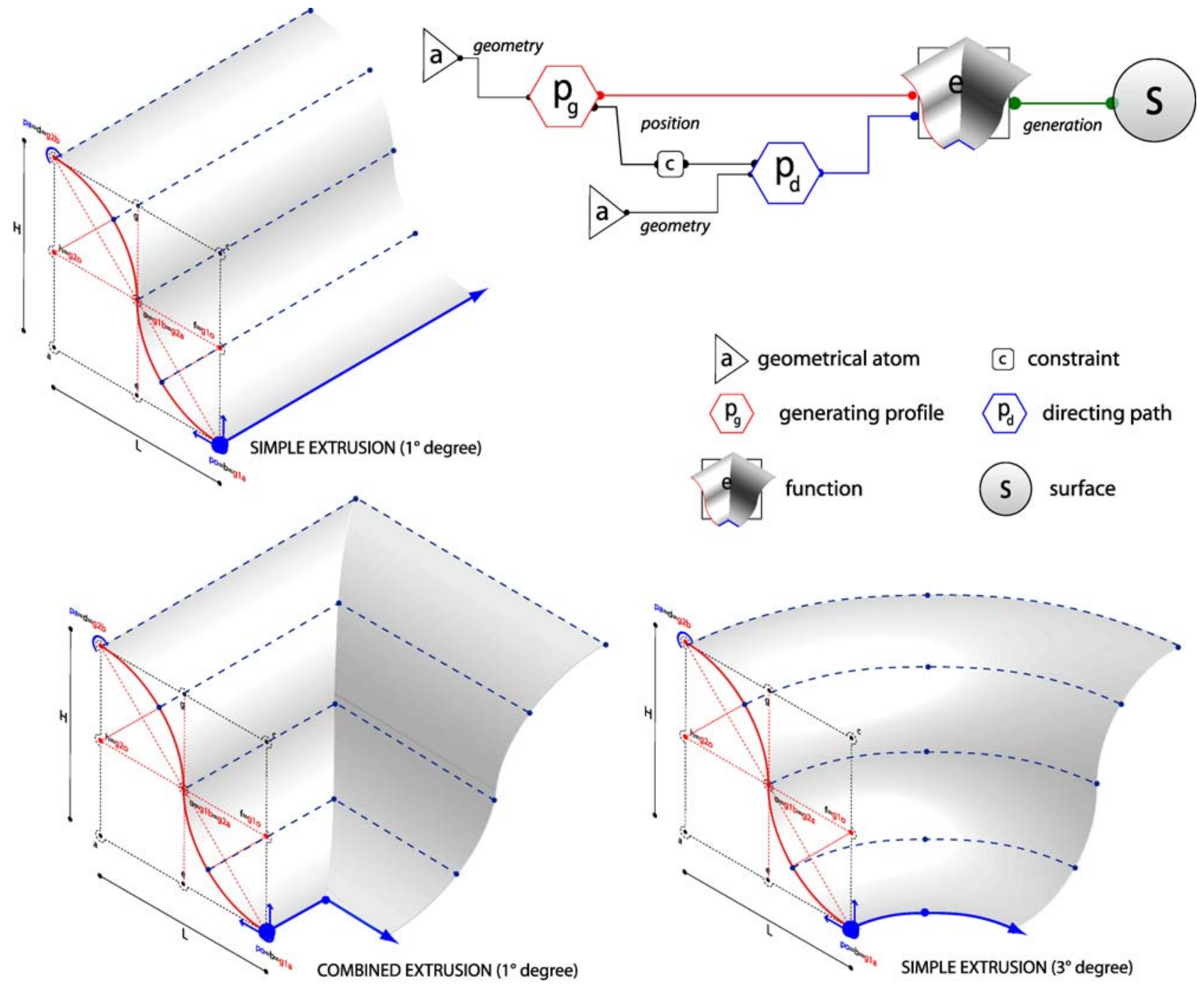

Fig. 13. Modeling functions for the surface generation

the geometrical description elements in a hierarchical structure: atoms/mouldings/parts of the profile/profile. In MEL the hierarchical relations can be formalized by the DAG (direct acyclic graph). These relations specifically relate to the simple transformations in space. To give an example, in a hierarchical relation, the attributes of position, rotation and scale of the son entity are expressed in the local reference mark of the parent entity. That enables us to select, handle or deform the parts of the element according to a semantic cutting. In its treaty of architecture Palladio provides the thesaurus to describe the various parts of the examined object: "... The capital ought to be in height half the diameter of the column, and is to be divided into three parts. The upper part is given to the abaco and cimacio. The cimacio is two of the five parts thereof, which must be divided into three parts; with the one the listello is made, and with the other two the gola. The second principal part is divided into three equal parts, one to be given to the anelli or annulets, or gradetti, which three are equal. The other two remain for the ovolo, which projects two thirds of its height. The third part is for the Collarino ..." [21].

In Fig. 16 one can notice the differences between logics of cutting between the geometrical and the semantic description of the formalized element. First of all it is noticed that an architectural atom (moulding) often results from a series of geometrical atoms. Then one can observe that geometrical description must take into account all discontinuities along the profile (on the two axes) and to separate the transitions, concave and convex, from the linear segments with which they are in continu- 


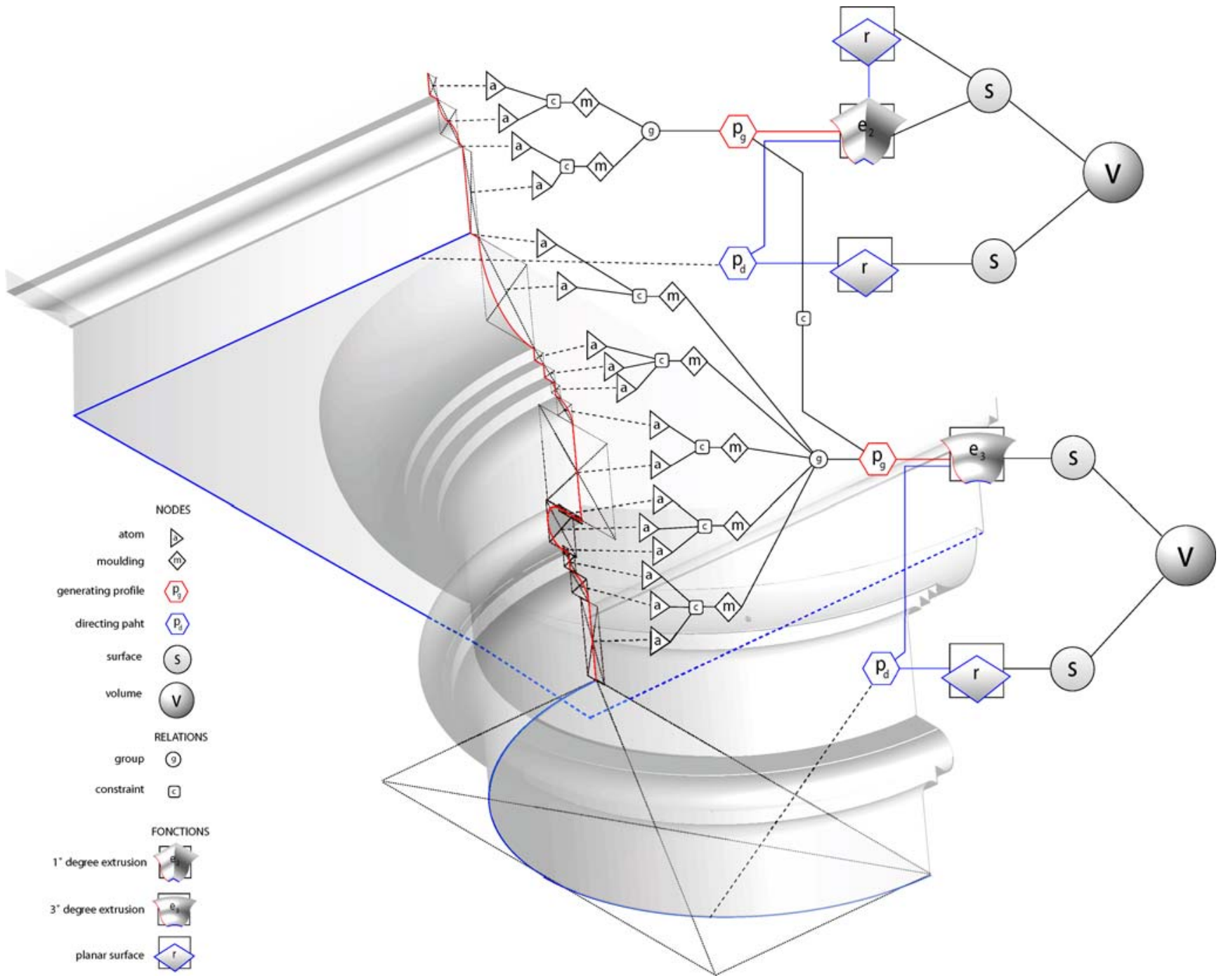

Fig. 14. Geometrical description of a Doric capital starting from the Palladio's treaty

ity. On the other hand a semantic description results from the assignment of an architectural term to the parts of the object according only to a vertical division. The architectural term identifying a moulding indeed indicates a transition in surface from the element, but it does not specify with precision its space perimeter, nor all the geometrical atoms that belong to him. We deduce from it that a semantic description relates to a mental representation of the shape that it is not always sufficient for an exhaustive description of its morphology. That justifies a part of our approach: we add a semantic layer to a geometrical representation. But that suggests at the same time the difficulty that an opposite approach can pose (to generate a geometrical representation starting from a semantic description). We used formalized primitives for two distinct applications:
- To instantiate architectural primitives in a point cloud with the double aim of reconstructing the shape of the analyzed element and automatically obtaining relevant measurements

- To constitute a library of architectural elements by the simple declaration of a sequence of mouldings

In the first case, one builds a semantic layer on the geometrical representation of a scanned object. In the second case, one builds a geometrical representation starting from a semantic description.

\subsection{Instantiation of architectural primitives in a point} cloud

The concept of construction history, on which our formalization approach is based, guarantees the relationship be- 


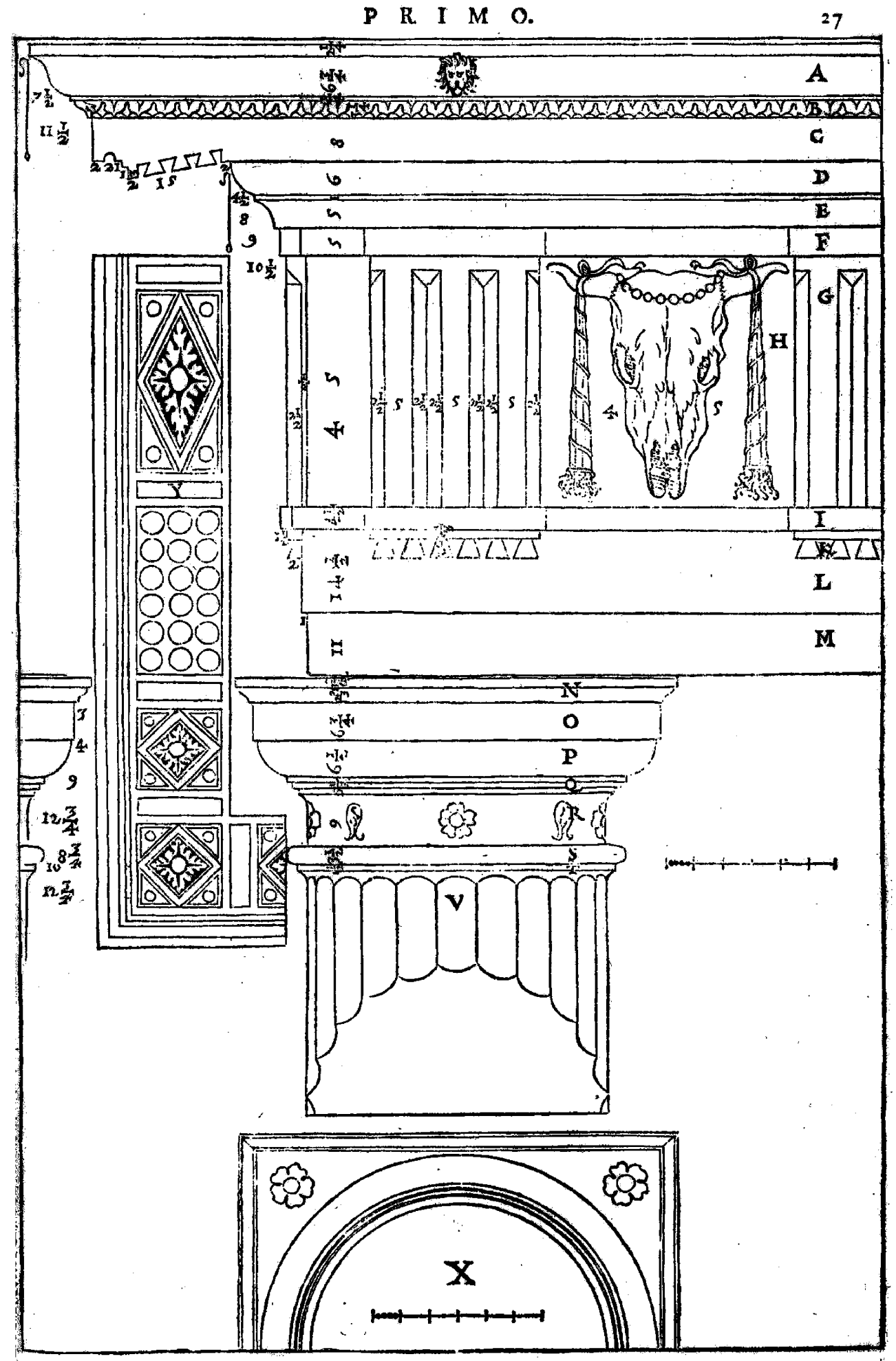

Fig. 15. Description of the Doric capital in the Palladio's treaty [21] 

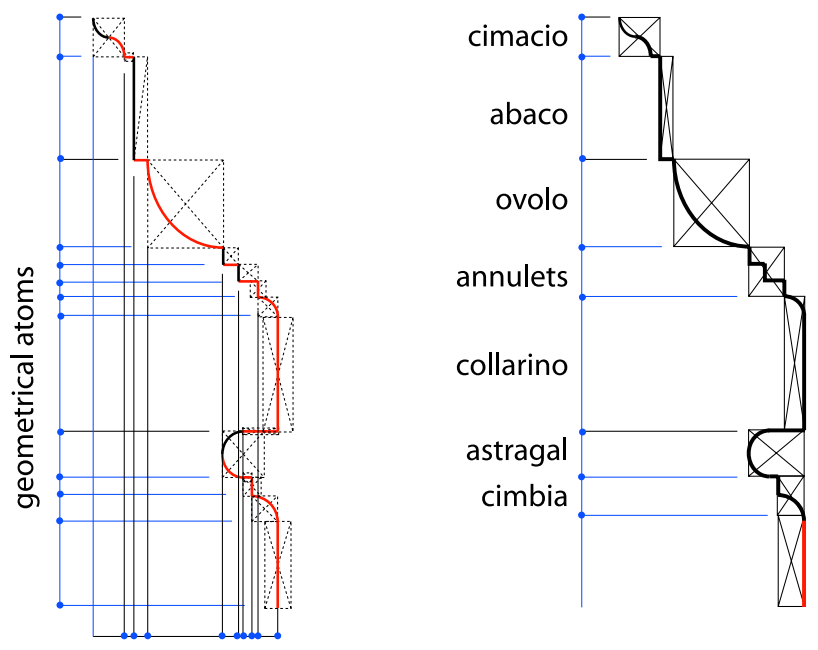

tween atoms and generated surfaces. This property is exploited by a process of instantiation based on three stages.

- In the first, one introduces into the scene the primitive inside a bounding box formed by a deformable parallelepiped and including two intersection planes according to the horizontal and the vertical construction profile of the primitive. Translations, rotations and scaling can be applied to the whole primitive and its positioning can be controlled in real time on the two intersection planes. In this stage, one simply seeks to locate the ends of the

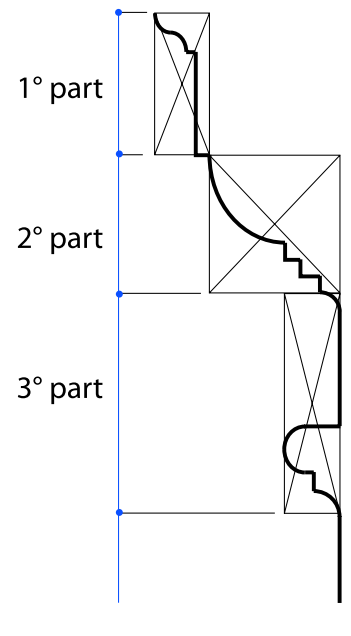

Fig. 16. Semantic description of a Doric capital starting from the Palladio's treaty element without being concerned with effective coincidences between the primitive and the point cloud (see Fig. 17).

- The second stage consists in deforming under-constraint the geometrical atoms of the primitive. This stage also exploits the intersection planes. The logic of deformation follows an upward sequence. Thanks to the chain of formalized constraints, the deformations applied to the first atom determine the update of the positions on the remainder of the chain (see Fig. 18). The degrees of freedom of each atom are defined in the moment
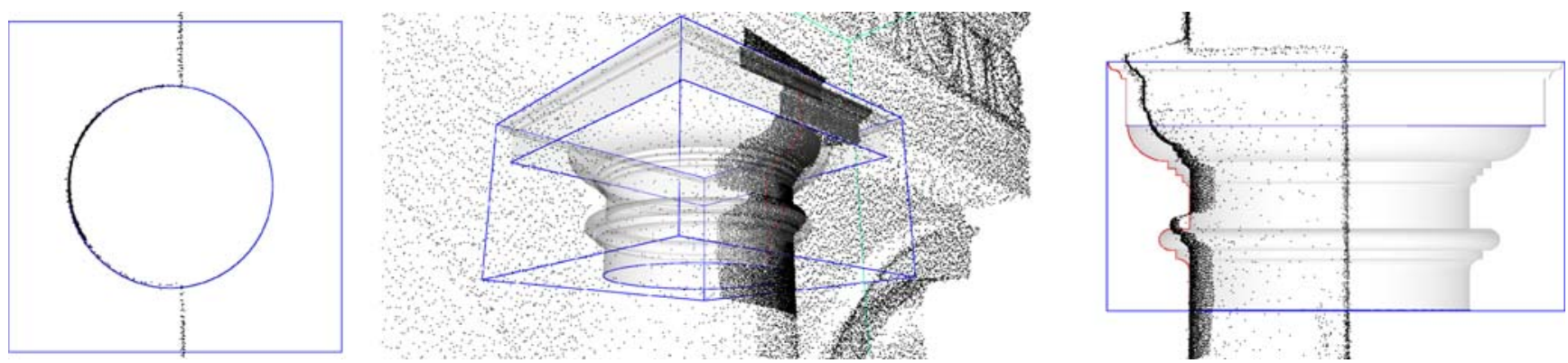

Fig. 17. First stage of instantiation of the primitive. From left to right: the horizontal intersection plans, the primitive in the point cloud, the vertical intersection plan
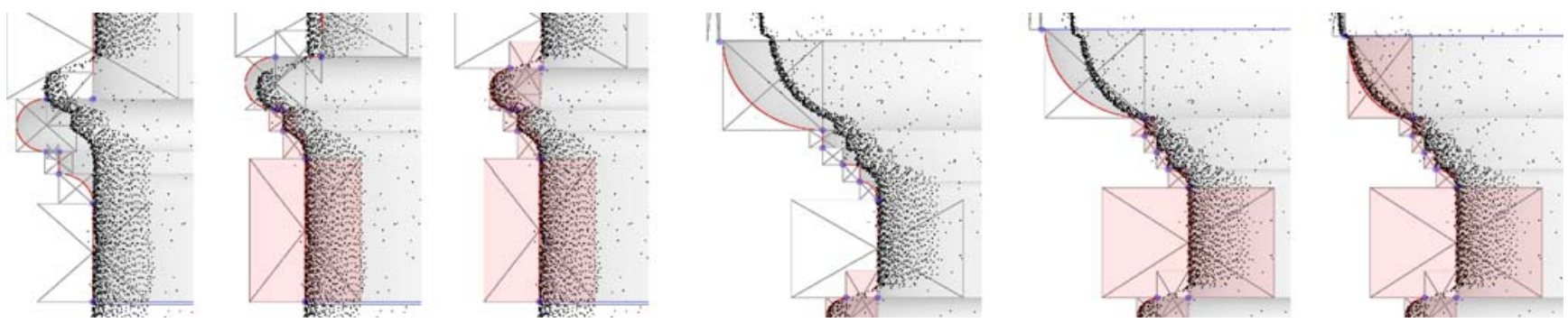

Fig. 18. Second stage of the instantiation of the primitive: under-constraint deformation of geometrical atoms 

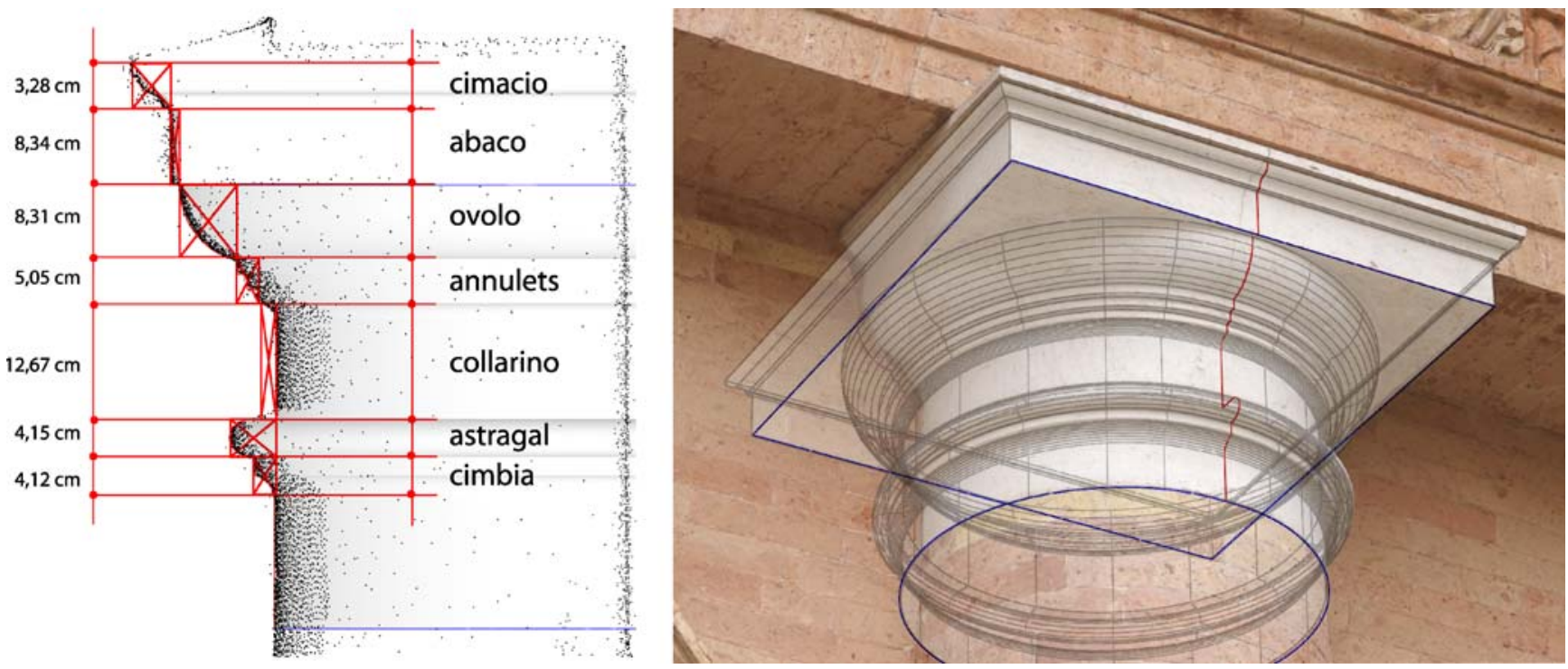

Fig. 19a,b. The primitive instantied on the point cloud. On the left $\mathbf{b}$, the vertical profile with dimensional information. On the right a, the primitive projected on a photography oriented on the point cloud

of formalization. However, in the case of the application of a rotation, the deformation of surfaces can cause a degradation of the final form of the primitive. For this reason it would also be necessary to take into account the formalization of constraints of orientation (limits of displacement, rotation and deformation of the geometrical atoms).

- The third stage (optional) allows controlling the lowest level of geometrical description: atoms. In this case, the transformations can be applied to the control points of $B$-splines. This stage is important to finely adapt the profiles on the point cloud: indeed, the deformations applied to the geometrical atoms in the second stage of instantiation process relate to the bounding boxes that contains them. That constitutes an important limitation if one wants to adapt the profiles of the primitive to the co-ordinates resulting from the laser scanning. Indeed, each part of the surveyed shape presents various imperfections due to the decay of materials or more simply to the errors of realization.

Thanks to a hybrid registration of different sources [5], the whole procedure of instantiation can also exploit an oriented photograph as visual support where the point cloud remains a limited support of interpretation (see Fig. 19a). This procedure is currently manual, but its organization in progressive stages of adjustment offers the possibility of integrating automatisms. Finally, the relations established between the two levels of description (geometrical and semantic) enable us to extract from the geometrical representation a set of relevant dimensional information (see
Fig. 19b). For example, after the instantiation process, we can know the height of the abaco of the capital instead of the simple distance between two points.

\subsection{Modeling of architectural primitives per declaration of mouldings}

Another type of exploitation of our approach relates to the constitution of a library of elements by simple declarations of a sequence of mouldings. We focused on the problem of adapting the declarative modeling approach [17] for the semi-automatic generation of profiled elements of classical architecture. Selected logic is based on the sequential aggregation of mouldings forming a profile in an upward order and according to the principal parts of the object. For better explaining our problem we show the example of the balusters. The baluster is a small vertical element normally divided into three parts (base, body and capital) and whose form is generally based on the revolution of a profile around a vertical axis (see Fig. 20). This revolution can have various levels of smoothing starting from a horizontal square, hexagonal, octagonal or circular profile. According to the cases, different horizontal profiles can represent the shape of the various parts of the element. From the identification of this simple structure of description, a big variety of balusters can be described (see Fig. 21). An in-depth study on this element is provided by Wittkover [35]. The procedure developed allows to automatically generate balusters starting from a sequential description of mouldings associated with a path. For the dimensioning of the atomic units three strategies are possible: 


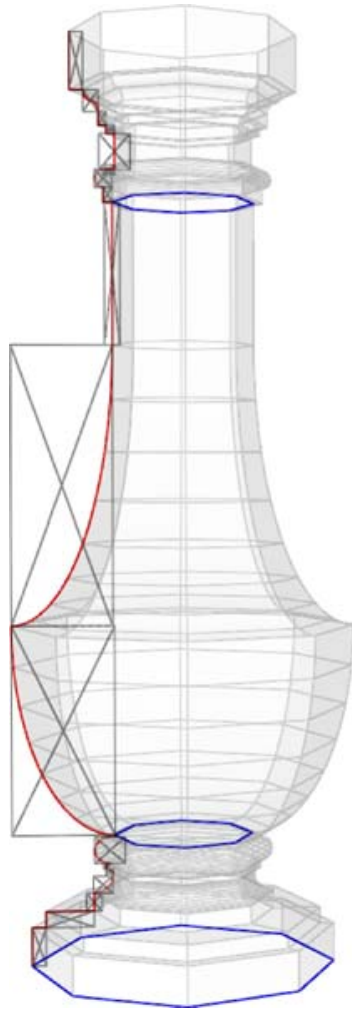

Fig. 20. The modeling of a baluster by declaration of a sequence of geometrical atoms

- Introduction of the dimensional attributes to the nodes atoms according to information contained into the documentary source

- Deformation of the atoms and the path on a twodimensional support (digitized treaty of architecture)

- Deformation of the atoms and the path on a point cloud of a scanned element
Another approach that we experimented uses an aggregation of entities of a higher nature, the mouldings. In this case, the geometrical primitives are geometrical sets of atoms already connected in groups. This king of modeling per declaration appears very effective for the geometrical construction of entities by a declaration of a sequence of architectural terms (mouldings) and without a direct handling of the geometry. For example, the base is an element characterized by a sequence of mouldings in revolution around the vertical axis: its modeling can result from the simple list of the mouldings composing its generating profile. Figure 22 illustrates three bases modeled starting from the declaration of a sequence of mouldings.

\subsection{Library of elements}

One of the most important advantages of our formalization approach resides in the possibility of separating the description of the elements from their geometrical representation. That makes possible the exploitation of the same description by various procedures of geometrical interpretation and also preserves the data independently of a specific modeling language. Indeed, several methods of geometrical translation could be studied with an aim of exploiting the collected information. We developed a solution for sharing a library of elements based on the interaction between a relational database and a $3 \mathrm{D}$ modeler. This procedure interprets the descriptions stored in the database by translating them into a MEL script. The recording in the data base organizes the geometrical and parametric description of each entity according to a pre-established structure with five fields (atoms, constraints, profiles, surfaces and vocabulary terms). We intend to entirely reproduce this structure in XML format. A MEL function allows introducing a web browser inside an interface lay-
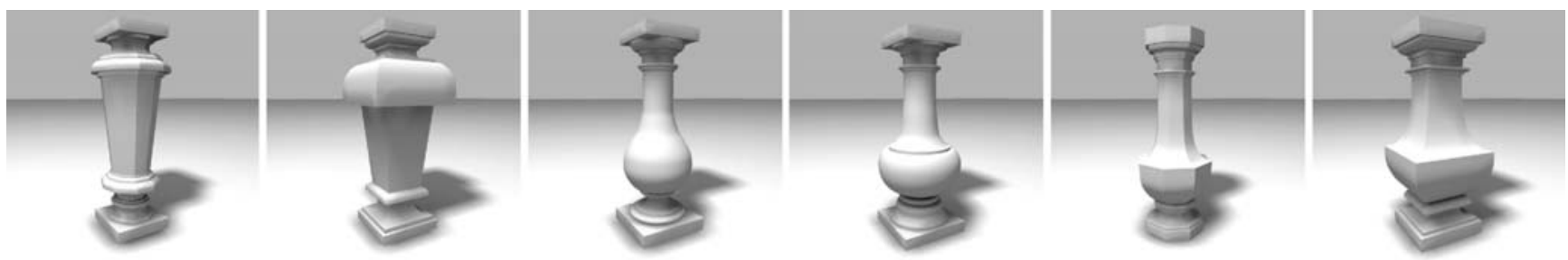

Fig. 21. Balusters modeled by declaration of a sequence of geometrical atoms
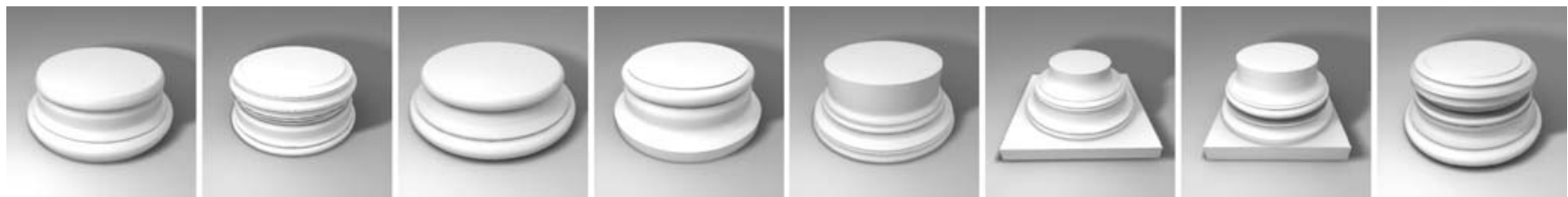

Fig. 22. Bases modeled by declaration of a sequence of mouldings 


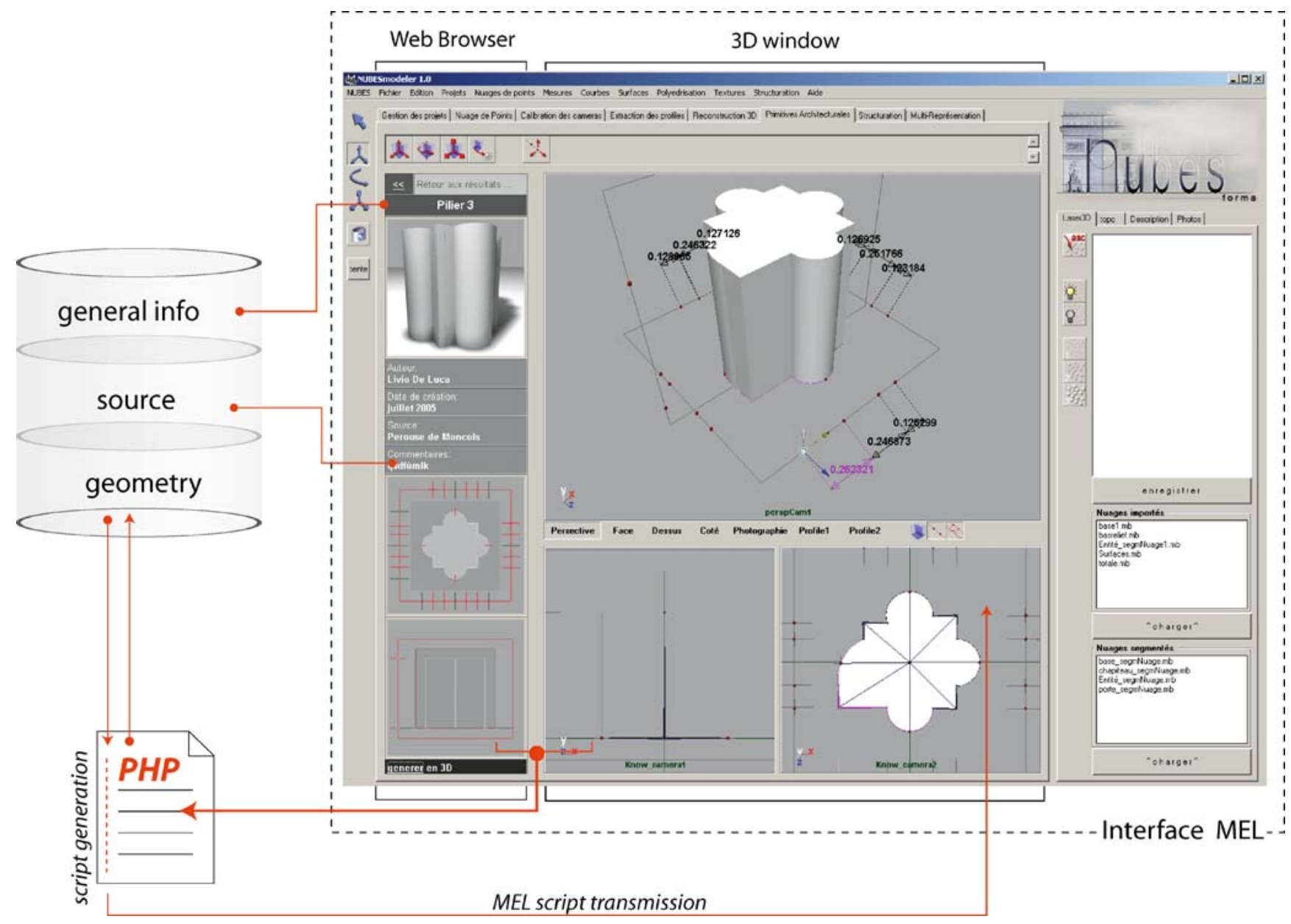

Fig. 23. Diagram of relations between the data base and the 3D modeler

out. This browser can receive MEL scripts starting from an URL. For the automatic generation of a primitive a PHP procedure extracts the values stored in the database and uses them to generate a modeling script in MEL. Once generated, the primitive keeps the relation with their construction history allowing under-constraints deformations (see Fig. 23).

\section{Model structuring and multi-representation}

\subsection{The building as a system of knowledge}

To associate semantics to the architectural shape forces above all to regard the building as a system of knowledge, then to extract a model from it description, and finally to define its representation according to the objectives of the analysis. A system of architectural knowledge can be described as a collection of structured objects identified by a precise vocabulary $[19,24]$. Several researches concen- trated on the development of classifications of architectural elements in theoretical frameworks [32] or in applications of the geometrical modeling $[11,19]$. Beyond the identification of the architectural primitives, the description of the structuring of these elements in an ordered unit requires observations of a more complex nature. Goulette [14] identified three types of relations between the elements one can find into the vocabulary of the architect:

- Topological relations. They are the relations that express the relative positioning of an element, or a part of element, inside a unit device.

- Part-unit relations. The description of a building can be led by regrouping simple elements in a unitary whole or ordered sets. These relations express the hierarchical organization which one can read in the composition of a building: the elements started from a homogeneous whole, itself being able to have started from a unit of a higher nature.

- Composition relations. They are diagrams of composition resting on a set of rules controlling the relative 
positioning and the dimensioning of a set of elements in a general geometrical layout.

We turn our attention on part-unit relations because the other types of relations relate rather to the problems of architectural composition than to the analysis of existing buildings where these relations are already explicit. We distinguish three types of part-unit relations:

- Piece-all. The piece-all relations express the way in which the under-parts of an object are organized to form a single element. The treaties of architecture normally offer a term for each under-part of the element. This cutting corresponds sometimes to the true physical divisions of the object, and in other cases, it refers to the geometrical transitions that the shape expresses.

- Member-collection. These types of relations are at the base of typological classifications. Compared to the identification of a type, these relations can gather the elements of categories according to comparison criteria. In architecture, these classifications are based normally on the study of the stylistic currents related to historical periods or geographical areas.

- Component-assembly. They are relations that characterize the logic of presentation of treaties of classical architecture. They express the architectural sets according to a logic based on the analysis of the composition of the building. The composition of "harmonious" sets is led by principles of scheduling like proportions, rhythm and symmetry.

\subsection{Semantic description of existing buildings}

In the research we just quoted, it is obvious that the logic of the semantic cutting of a building is always constrained to the description of ideal models. These approaches are indeed founded on the structuring of symbolic shapes. However our objective consists in adding a semantic layer to the description of the morphology of existing buildings. Blaise [2] showed that for the architectural analysis, approaches of classification by intension (association of an ideal model to a real element) are sometimes incompatible with the requirements of architectural heritage studies, whereas approaches by extension (extraction and grouping of descriptors common to several elements) seem more relevant. In fact, the architectural element, as a symbolic shape, belongs indeed mainly to the field of the mental representation [14]: it is an abstracted object used to think and conceive an architectural project. Moreover, it should be noticed that knowledge that intervenes in a semantic cutting of a building always relates to an objective of analysis. As an example (see Fig. 24) the logic of cutting according to the vocabulary of the architect is in contrast with divisions between the physical units that make the object: divisions between the base, the shaft and the capital of the column do not coincide with the physi-
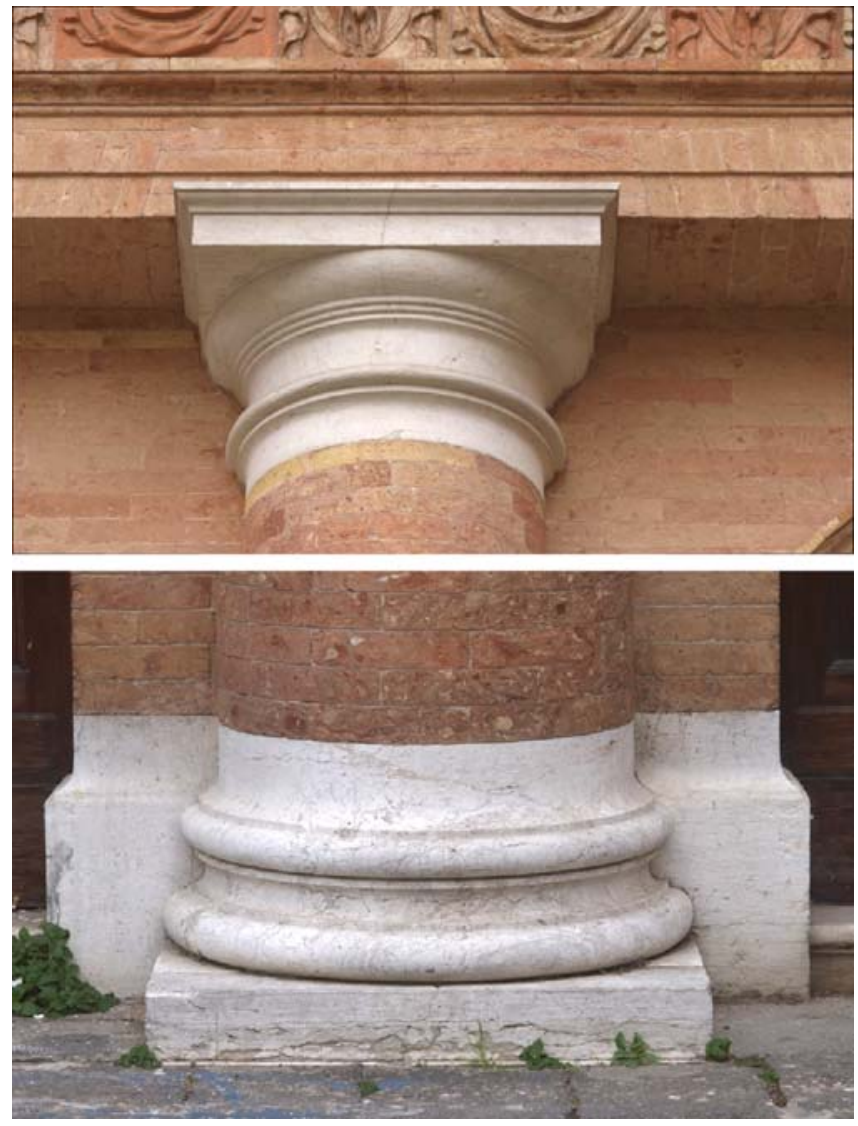

Fig. 24. Ambiguities between the vocabulary of the architect and physical divisions of the elements

cal borders of the elements. The astragale and the cimbia, which in the vocabulary of the architect constitute the ends of the shaft of the column, form, in the carried out building, part of the capital and respectively the base (due probably to problems of realization). This type of ambiguity explains the difficulties that a semantic description may meet within a framework of structuring of three-dimensional entities of buildings. With the aim of designing a methodological framework for the representation of buildings based on their semantic description, we introduce the "point of view" as a concept determining the structuring of the model. The concept of point of view includes three aspects:

- The use of a vocabulary to isolate elements from the building

- The identification of a logic for the regrouping of these elements in a coherent unit

- The choice of a type of representation able to extract from the shape the information necessary to the analysis

In agreement with the principles introduced by Falcidieno et al. [8], we built around the morphology of the building 
a description model defined by three distinct levels: semantics, structure, representation. Consequently, we distinguish three phases passing from the restitution of the morphology of the object to its possible representations.

- Semantic level. A first phase consists of isolating concepts (terms of description) and associating to them parts of the shape. That underlines the need to lead a morphological cutting according to a precise vocabulary used by a specific analysis (see Fig. 25).

- Structural level. The second phase makes it possible to establish a graph of relations between these concepts and to organize the elements of the scene compared to a requirement of description. To support this phase we use a symbolic notation, in 3D space, of the part-unit relations established between the isolated elements. We use as a starting point the logic of structuring introduced by Heine [15]. A 3D graph (tree structure in space), whose configuration depends on the handling (hierarchical relations) of a set of terms in a list, is established using specifically defined nodes (see Fig. 26):

- A morphological entity, which results from a semantic cutting, constitutes a concept identified by the user for the description of the building which can
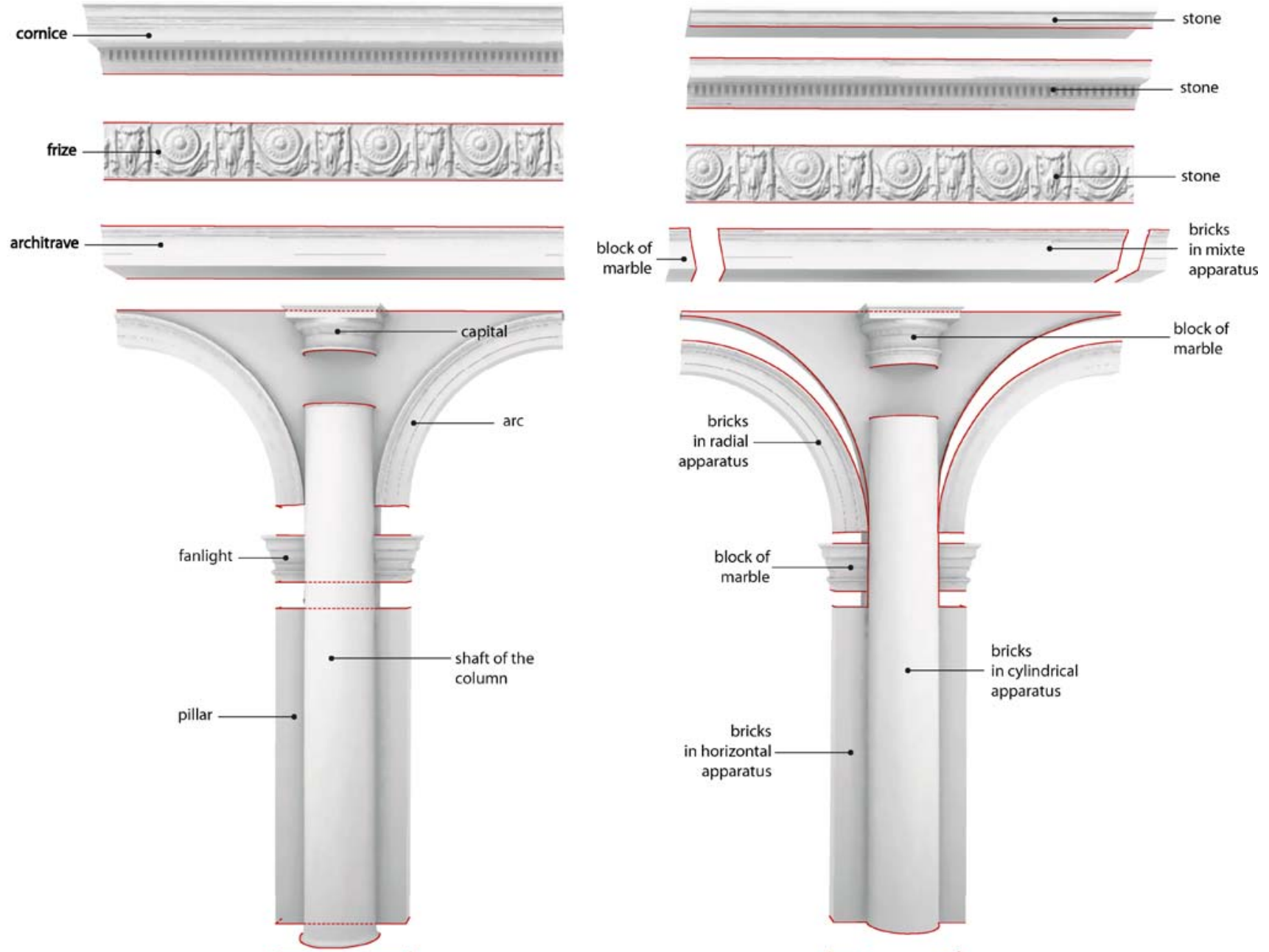

foot of wall

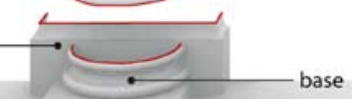

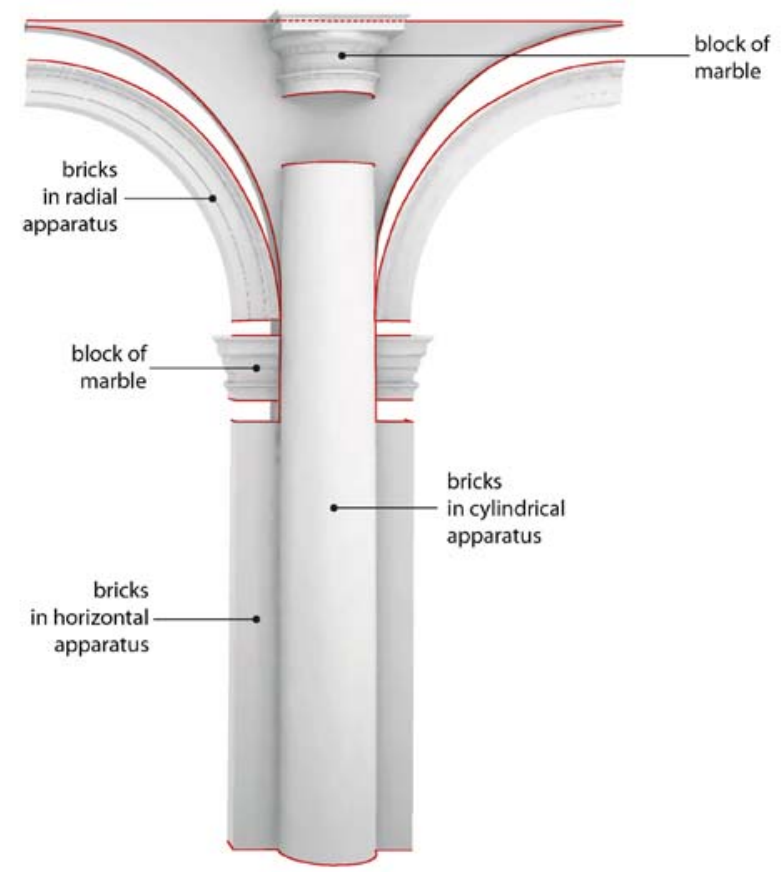

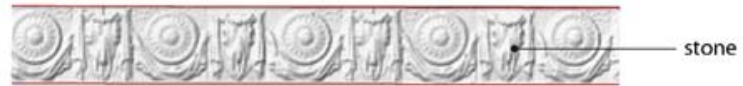

block of marble

Fig. 25. Morphological cuttings of the analyzed object according to two different analyses: the vocabulary of the architect and the construction techniques 


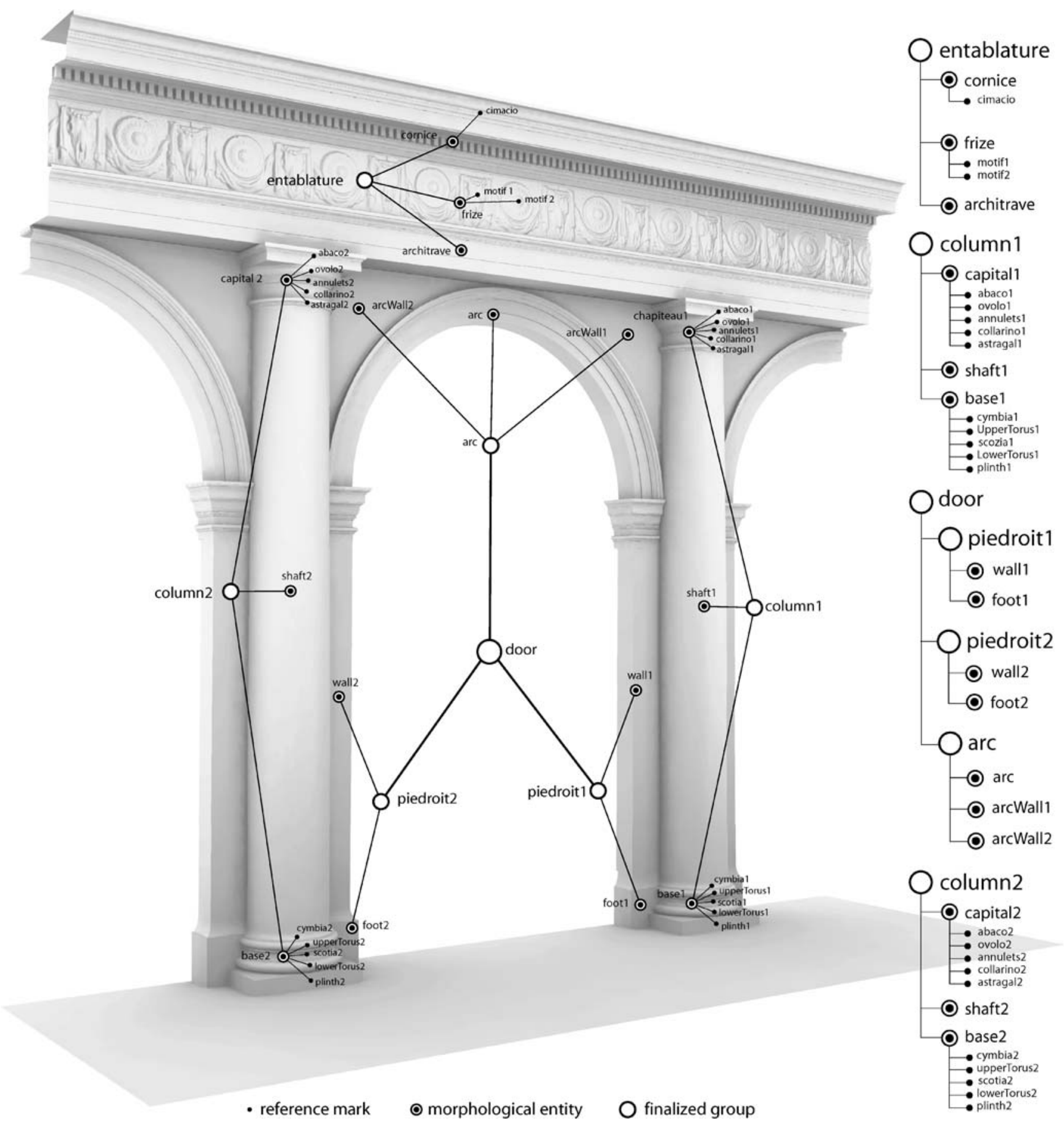

Fig. 26. 3D graph for the semantic description of the building

be associated to one or more geometrical representations.

- A finalized group is a node that gathers morphological entities and does not have a geometrical representation. Its spatial extension results indeed from the union of the bounding boxes including the entities that belong to it.
- A reference mark indicates a particular aspect inside a morphological entity. For example the moulding of an element, a character of a low-relief, or the decay of a material, etc.

- Representation level. The last phase allows associating various representations to the same morphological entity according to various objectives of description. Start- 


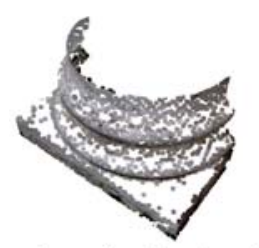

colored poin cloud

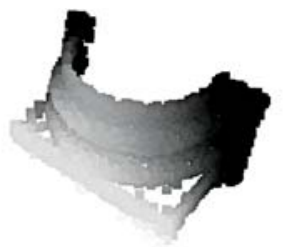

distance map
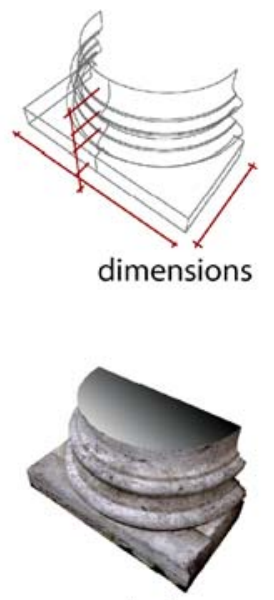

texured polygons

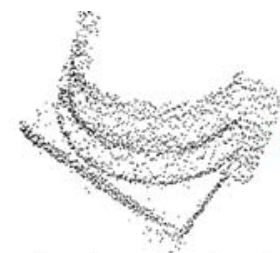

simple point cloud

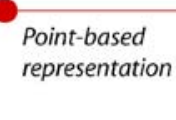

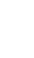

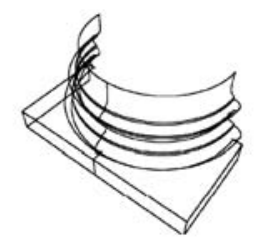

profiles

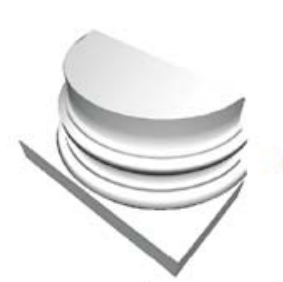

Polygon-based

representation

polygons

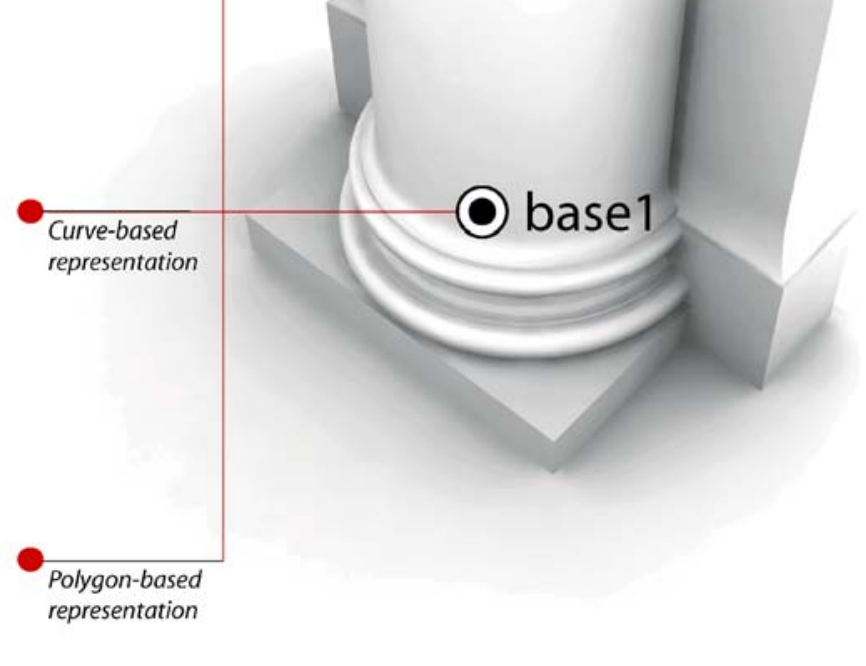

Fig. 27. Multiple representations organized around a morphological entity

ing from three geometrical bases (points, curves, polyhedrons), we classify various types of representations (basic and colored point clouds, depth maps, parametrical surfaces, enriched polyhedrons, etc.) focusing on the type of description they allow, the techniques necessary to their generation and the information they convey (see Fig. 27).

As we will see, this division confers an important degree of freedom in the exploitation of the data resulting from the surveying of the building because, starting from the same geometrical model, one can work out various semantic descriptions that exploit a multirepresentation system. Moreover, the model of description of the building is not only used for the structuring of the three-dimensional model, but may become the common denominator for the establishment of bilateral relations between morphology of the object and heterogeneous information.

\subsection{Points of view on the building}

Various researches concentrate today on the multi-representations of entities in various research fields. Among this works, some are applied to cartography [31]. In this case, the multi-representations of two-dimensional entities are exploited to guarantee a level of graphic in- formation adequate to a given scale. Others exploit the multi-representations to structure various levels of polyhedric complexity according to the various exploitations of the same 3D model [16]. All these works organize several representations of the same object while being always based on the same geometrical base (2D vectors or 3D polygons). The difference among the multiple representations thus relates to the quantity of geometrical information they contain. However, the analysis of the architectural heritage can use techniques of representation that exploit various geometrical bases. It is therefore important to introduce a distinction between the concepts of resolution and representation: a representation results from a development technique that allows describing the shape of an object according to a geometrical base and to a resolution level. A second problem relates to the possibility of making the collected data and information accessible to an important variety of users (researchers, administrators, general public, etc.). To do this, a representation system must necessarily reflect the various points of view of disciplines that are interested in the study of the building, its conservation and its valorization. Division between three parallel levels of description (semantic, structure and representation) can thus be exploited to construct a representation of the building according to a specific 

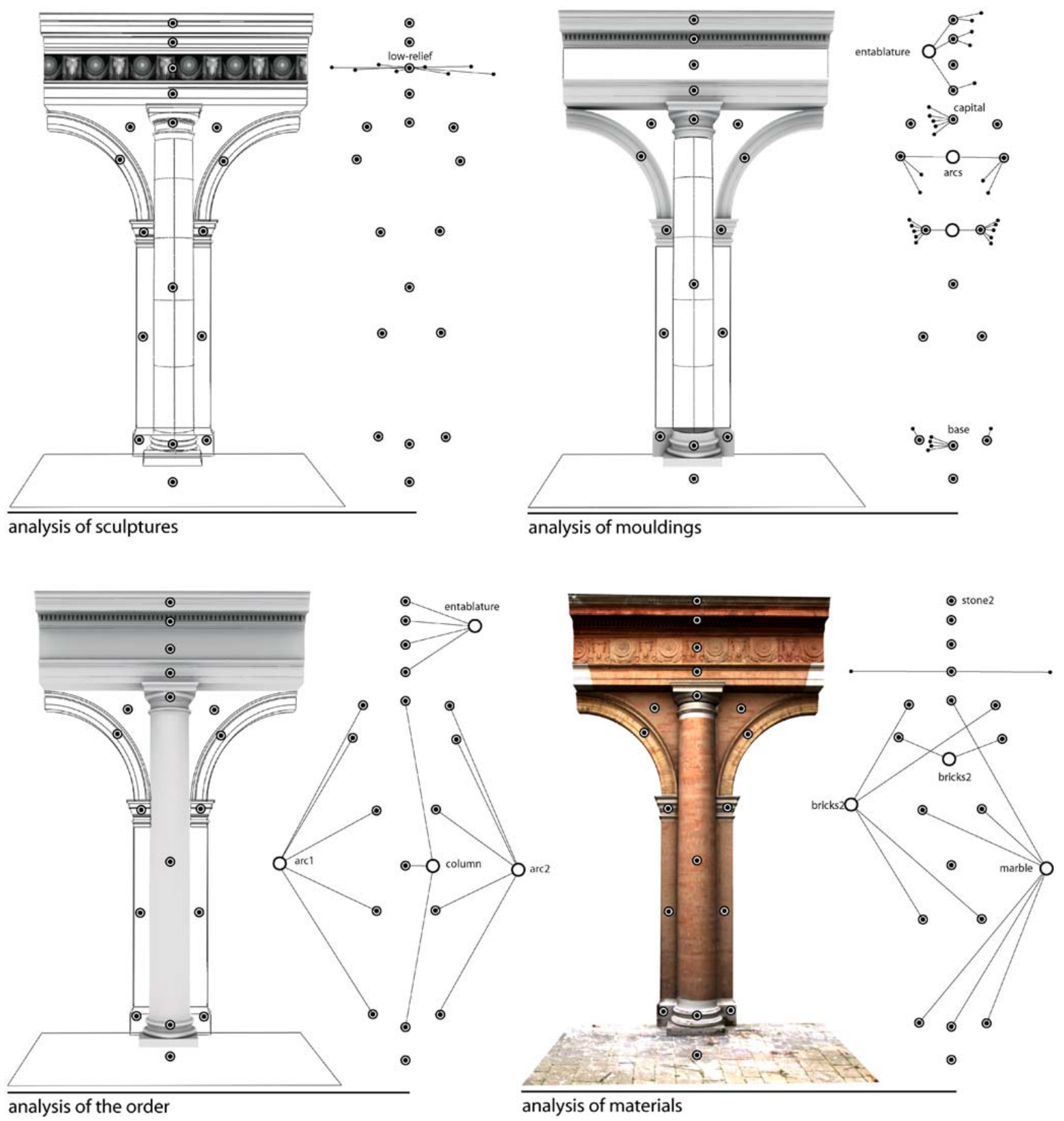

Fig. 28. Four "points of view" on the studied object elaborated starting from the same morphological cutting

need of analysis. The logic of the system is based on the requirement of declining the structure of description to allow the true freedom of data organization. Figure 28 presents four different "points of view" of the same architectural object constructed with our description approach.

\section{Conclusions}

The problems tackled in this article relates to an approach to understanding, reconstructing, structuring and representing architectural elements. This approach suggests an- 
swers to a certain number of problems in the field of the architectural representation, but it presents some gaps that must be analyzed. Indeed, even if the restitution of the shape based on a priori models can appear as an interesting solution for the dimensional comparison of repetitive elements, its implementation presents problems not yet solved. The positioning of the architectural primitive in the point-cloud is currently based on arbitrary estimations of the user. With an aim of making this procedure more robust it will be necessary to implement best-fit techniques according to various aspects: surfaces [7], characteristic profiles [22] or construction history [25]. In the same spirit, the methods using graph grammar for the automatic rebuilding of shapes [10] could be taken into account.

The principle introduced for the description of the building was tested only on buildings of classical language whose architectural composition is characterized by a clear organization of the composing elements. Other stylistic currents are likely to be studied by a formalization of this type. In the same way, it is necessary to hold into account the composition relations, which rest on a set of rules controlling the relative positioning and the dimensioning of elements in a general geometrical layout. This
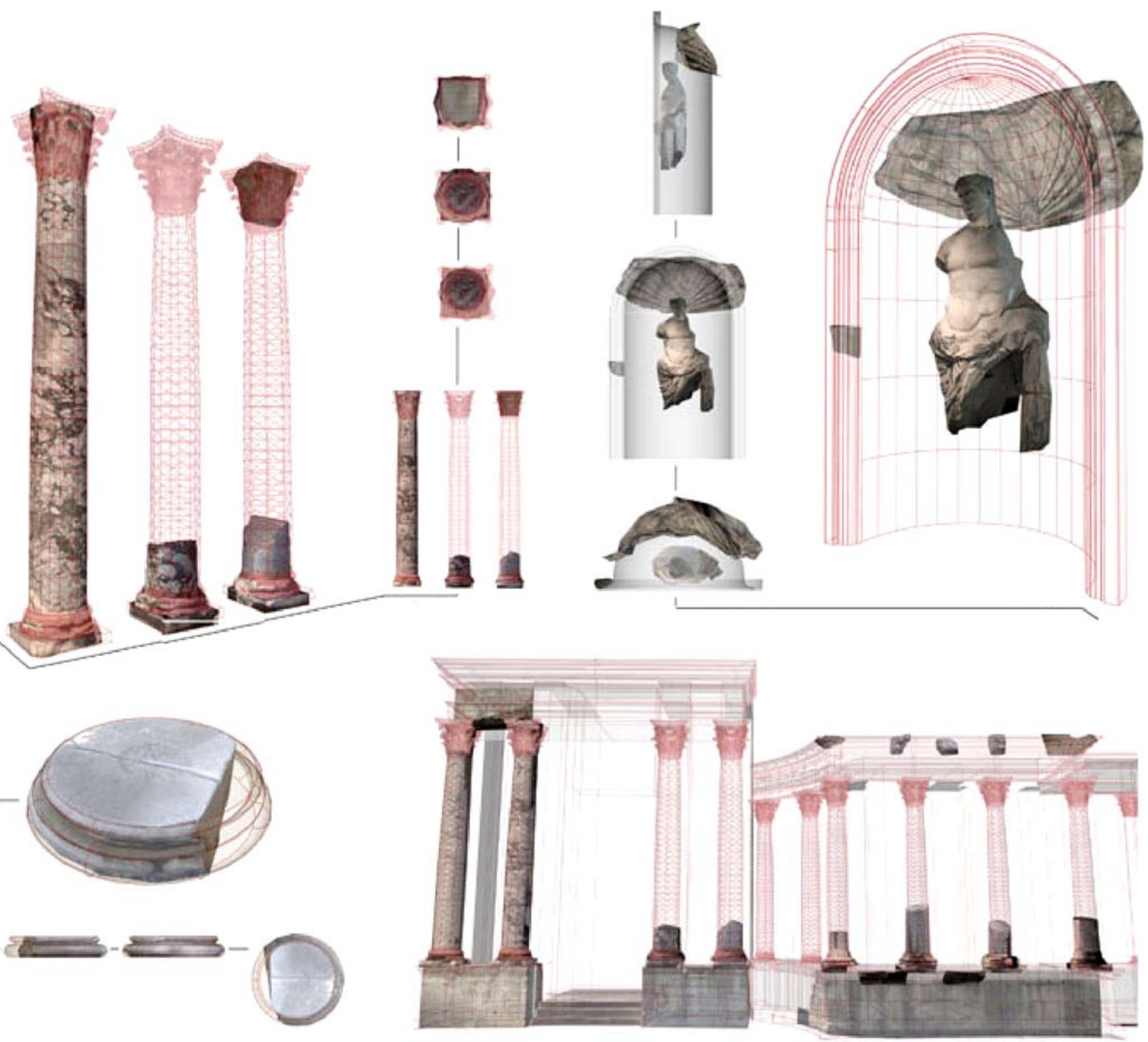

Fig. 29. Ideal models (in wireframe) instantiated on the archaeological rests (reconstructed) of the Roman theater in Arles 
aspect may, in the same time, appear relevant to understanding the architectural composition that characterizes an existing building and to the development of restitution assumptions of a partially or totally destroyed building. The problem consists of formalizing the proportion systems that interest the buildings of a great part of the history of architecture [30]. This type of reasoning may for example be applied to the representation of restitution assumptions resulting from a comparison between ideal models and reconstructed fragments [3] (see Fig. 29). In this direction, the concept of multi-representation could play an important role: to organize around the description of the building a set of representations corresponding to the various levels of its hypothetical restitution.

\section{References}

1. Alberti, L.B.: De re aedificatoria libri decem. Biblioteca Apostolica Vaticana Vatican (1452)

2. Blaise, J.Y.: Le formalisme objet appliqué à l'étude de l'edifice patrimoniale: problèmes de modélisation et d'échanges de données sur le réseau Internet. Dissertation, Université d'Aix-Marseille III (2003)

3. Blaise, J.Y., Domenico, F., De Luca, L., Dudek, I.: Architectural Modelling and Information Interfacing: Learning from Three Case Studies. In: Proceedings of 26th International Conference on Information Technology Interfaces, Dubrovnik, Croatia (2004)

4. Thompson, D.W.: On Growth and Form. Cambridge University Press, Cambridge (1942)

5. De Luca, L., Véron, P., Florenzano, M.: Reverse engineering of architectural buildings based on a hybrid modeling approach. Comput. Graph. 30(2), 160-176 (2006)

6. Desargues, G.: Bruillon projet d'exemple d'une manière universelle du S.G.D. touchant la pratique du trait à preuves pour la coupe des pierres en Architecture. Paris (1640)

7. Eck, M., Hoppe, H.: Automatic reconstruction of $B$-Spline surfaces of arbitrary topological type. In: Proceedings of SIGGRAPH '96, pp. 325-334 (1996)

8. Falcidieno, B., Spagnuolo, M.: A shape-abstraction paradigm for modelling geometry and semantics. In: Proceeding of the International Conference on Computer Graphics. IEEE Computer Society, Los Alamitos, CA (1998)

9. Forssman, E.: Palladio e le colonne. Bollettino del Centro Internazionale di Studi di Architettura Andrea Palladio No. XX. Vicenza (1978)

10. Fuchs, F., Le Men, H.: Efficient Subgraph Isomorphism with 'A Priori, Knowledge. Application to 3D Reconstruction of Buildings for Cartography. In: Proceedings of Joint IAPR (Advances in Pattern Recognition), pp. 427- 436 (2000)

11. Gaiani, M.: Translating the architecture of the world into virtual reality and vice-versa: 7 years of experimentation with "conservation and representation" at OFF. In: Proceedings of Heritage Applications of 3D Digital Imaging. NRC Ottawa (1999)

12. Ginouvès, R., Martin, R.: Dictionnaire methodique d'architecture Grecque et romaine. Tome II. Athènes, Rome (1992)

13. Gould, D.: Complete Maya Programming: An Extensive Guide to MEL and C++API. Kaufmann, San Francisco (2002)

14. Goulette, F.: Sémantique formelle de l'espace: Application au raisonnement spatial qualitatif en architecture. Intellectica: Revue de l'Association pour la Recherche Cognitive 29, 9-34 (1999)

15. Heine, E.: High precision building documentation: Element definition and data structuring. In: Proceedings of the ICOMOS \& ISPRS Committee for the Documentation of Cultural Heritage, Working Group II, Recife, Brazil (1999)

16. Léon, J.C.: Structure d'un environnement de Conception Multi-vues et Multi-représentation. In: Actes des Journées Modeleurs Géométriques, Grenoble (1997)

17. Lucas, M., Desmontils, E.: Les modeleurs déclaratifs. Revue Internationale de CFAO et d'Informatique graphique 10(6), 559-586 (1995)

18. Migliari, R., Docci, L.: Geometria e Architettura. Gangemi editore, Rome (2000)

19. Mitchell, W.J.: The Logic of Architecture. Design, Computation, and Cognition. MIT Press, Cambridge, Massachusetts (1990)

20. Monge, G.: Géométrie descriptive. Paris (1799)

21. Palladio, A.: The Four Books of Architecture (re-edn. 1965) Dover, New York (1750)

22. Plass, M., Stone, M.: Curve-fitting with piecewise parametric cubics. In: Proceedings of SIGGRAPH '83, pp. 229-239 (1983)

23. Perouse de Montclos, J.M.: Architecture vocabulaire. Principes d'analyse scientifique. Imprimerie Nationale, Paris (1972)

24. Quintrand, P., Autran, J., Florenzano, M., Fregier, M., Zoller, J.: La CAO en architecture. Hermes, Paris (1985)
25. Ramamoorthi, R., Arvo, J.: Creating generative models from range images. In: Proceedings of SIGGRAPH '99 (1999)

26. Rattner, D.: Parallel of the classical orders of architecture. Acanthus, New York (1998)

27. Remondino, F.: From point cloud to surface: the modeling and visualizaion problem. In: Proceedings of ISPRS International Workshop on Visualization and Animation of Reality-based 3D Models. Tarasp-Vulpera, Switzerland (2003)

28. Saint-Aubin, J.P.: Le relevé et la représentation de l'Architecture. Inventaire Général E.L.P., Paris (1992)

29. Serlio, S.: Tutte l'opere d'architettura et prospettiva. Venice (1619)

30. Scholfield, P.H.: The Theory of Proportions in Architecture. Cambridge University Press, Cambridge (1958)

31. Spaccapietra, S., Parent, C., Vangenot, C.: GIS Databases: From Multiscale to Multirepresentation. In: Proceedings of the International Workshop on Emerging Technologies for Geo-Based Applications. EPFL-DI-LBD Publisher, Ascona (2000)

32. Tzonis, A., Lefaivre, L.: Classical Architecture - The Poetics of Order. MIT Press, Cambridge (1986)

33. Ungers, O.M.: Ordo, pondo et mensura: criteri architettonici del Rinascimento. In: Million, H.A. (ed.): Rinascimento. Da Brunelleschi a Michelangelo. La rappresentazione dell'architettura. Milan (1994)

34. Vallée, L.: Spécimen de coupe de pierres, contenant les principes généraux du trait et leur application aux murs, aux plate-bande, aux berceaux, aux voûtes spheriques, aux voûtes de révolution, aux voûtes à base polygonale. Paris (1853)

35. Wittkover, R.: Il balustro rinascimentale e il Palladio. Bollettino del Centro Internazionale di Studi di Architettura Andrea Palladio No. X. Vicenza (1968)

36. Wittkower, R.: Architectural principles in the age of humanism. Wiley, London (1998) 